\title{
Dormancy in cereals (not too much, not so little): about the mechanisms behind this trait
}

\author{
María V. Rodríguez ${ }^{1 *}$, José M. Barrero², Francoise Corbineau ${ }^{3}$, Frank Gubler ${ }^{2}$ \\ and Roberto L. Benech-Arnold ${ }^{1}$ \\ ${ }^{1}$ IFEVA, Facultad de Agronomía, Universidad de Buenos Aires - CONICET, Av. San Martín 4453 \\ (C1417DSE) CABA, Argentina; ${ }^{2}$ CSIRO Agriculture Flagship, GPO Box 1600, Canberra ACT 2601, Australia; \\ ${ }^{3}$ Sorbonne Universités, Université Pierre et Marie Curie-Paris, UMR7622 CNRS-UPMC, Seed Biology team, \\ 4 place Jussieu, 75005 Paris, France
}

(Received 8 August 2014; accepted after revision 7 January 2015; first published online 19 March 2015)

\begin{abstract}
As in other cultivated species, dormancy can be seen as a problem in cereal production, either due to its short duration or to its long persistence. Indeed, cereal crops lacking enough dormancy at harvest can be exposed to pre-harvest sprouting damage, while a long-lasting dormancy can interfere with processes that rely on rapid germination, such as malting or the emergence of a uniform crop. Because the ancestors of cereal species evolved under very diverse environments worldwide, different mechanisms have arisen as a way of sensing an appropriate germination environment (a crucial factor for winter or summer annuals such as cereals). In addition, different species (and even different varieties within the same species) display diverse grain morphology, allowing some structures to impose dormancy in some cereals but not in others. As in seeds from many other species, the antagonism between the plant hormones abscisic acid and gibberellins is instrumental in cereal grains for the inception, expression, release and re-induction of dormancy. However, the way in which this antagonism operates is different for the various species and involves different molecular steps as regulatory sites. Environmental signals (i.e. temperature, light quality and quantity, oxygen levels) can modulate this hormonal control of dormancy differently, depending on the species. The practical implications of knowledge accumulated in this field are discussed.
\end{abstract}

*Correspondence

Email: mvr@agro.uba.ar
Keywords: cereal grain, cereals, pre-harvest sprouting, seed dormancy, seed germination

\section{Introduction}

\section{Duration of seed dormancy as related to cereal grain end-uses}

Cereals are the most important plant source of carbohydrates and proteins for human nutrition. Their many end-uses include bakery, milling, malting and brewery, and direct grain consumption. The cereal grain is also required to perform as the propagule for a new crop. From a botanical point of view, the cereal grain is a caryopsis (i.e. a dry, one-seeded fruit in which the pericarp, derived from the ovary wall, is fused to the seed coat) that can be 'dressed' (barley, oat, rice) or 'naked' (wheat, sorghum, maize), depending on the presence or not of the lemma, palea and in some cases, even glumes. Modern cereals (wheat, barley, maize, rice, sorghum, rye, triticale) originated from both temperate and tropical areas and developed very diverse responses to environmental factors such as temperature and light quality.

As defined elsewhere, dormant seeds are those that, due to some internal block, cannot germinate in the same conditions (i.e. water, air, temperature) that are suitable for the germination of non-dormant seeds (Bewley and Black, 1994; Bewley, 1997). As a trait, dormancy can be associated with a long list of adaptive advantages: seasonal detection, gap detection, spread of germination in time, depth detection, etc. Therefore, plants living in the wild (including the ancestors of modern cereals) can maximize the survivorship of 
their descendants due to the fine adjustment between germination opportunity and the environment provided by the different, and often sophisticated, dormancy mechanisms. This evident advantage derived from dormancy clearly disappears in cereal crops since, as with other crop species, emergence timing is carefully controlled to obtain maximum coincidence between plant phenology and environmental conditions that optimize yield and quality. Simultaneous emergence of all individuals is also required to ensure a homogeneous population for proper crop management. Hence, any variation in the timing of emergence because of the possible existence of remnant dormancy in the grain lot that is used to generate a new crop cannot be tolerated under production conditions. In addition, when industrial uses of grain involve germination (i.e. malting) a persistent dormancy precludes grain utilization until dormancy is terminated, thus increasing costs of storage and protection. For all these reasons, high selection pressure must have been exerted against dormancy throughout the domestication process. In some cases, this selection against dormancy has gone too far and grains are germinable even prior to crop harvest. This situation, combined with rainy or damp conditions prevailing during the last stages of maturation, may lead to germination on the mother plant, a phenomenon that is better known as pre-harvest sprouting (PHS). PHS has a wide range of consequences, all of them adverse, which go from the immediate loss of seed viability upon subsequent desiccation when the embryo has grown beyond the point at which it loses its desiccation tolerance, to a large reduction in seed longevity when embryo growth has not proceeded that far (Gualano et al., 2014). But, overall, the initiation of germination triggers the synthesis of enzymes that promote reserve mobilization, thus leading to dramatic alterations in grain quality.

The production problems associated with either a short- or a long-lasting dormancy have caught the attention of seed scientists, and thus an important proportion of dormancy research in recent years has been devoted to studies on cereal grains. Clearly, the final aim is to adjust the timing of dormancy loss to a precise time window (i.e. neither as early as to expose the crop to the risk of PHS, nor as late as to have a dormant seed lot at the time of subsequent sowing or industrial utilization). This time window can be particularly narrow in malting barley because the industry demands genotypes with low dormancy at harvest for immediate industrialization. Although some of the dormancy mechanisms operating in the cereal grains closely resemble those described for model organisms (i.e. Arabidopsis and Brachypodium distachyon), the cereals have many particularities and, moreover, different mechanisms appear to prevail in the distinct cereal species. In this sense, any new dormancy mechanism evidenced in a cereal grain must be seen, through its manipulation, as an opportunity to achieve the goal of adjusting the timing of dormancy release to the end-use of that grain. In this paper we review the progress made in our understanding of dormancy in cereals, pointing out similarities and differences between species and, overall, having in mind the possibility of detecting plausible routes to solve the above-mentioned practical problems.

\section{Environmental factors and dormancy expression, induction and release}

As in other species, freshly harvested cereal grains are considered to be dormant when they fail to germinate under apparently favourable hydric, gaseous and thermal conditions (Bewley and Black, 1994; Bewley, 1997). Dormancy in cereals is rarely absolute (i.e. no germination at all under any environment), but more often it is a relative phenomenon, and germination of dormant grains can occur only within a narrow range of environmental conditions when compared to nondormant grains. The way in which the expression of dormancy interacts with environmental factors, such as incubation temperature, depends on the genotype. Dormancy is very common in cereals originating either from temperate (wheat, barley, rye and oat) or from tropical areas (sorghum, rice, millet), while it is almost absent from maize at maturity (reviewed in Simpson, 1990). In temperate cereals, dormancy is expressed strongly (i.e. germination is inhibited) at relatively high temperatures, usually above $15-20^{\circ} \mathrm{C}$ (Corbineau and Côme, 1980, 1996; Corbineau et al., 1981, 1986; Benech-Arnold et al., 2006). On the contrary, dormant seeds from tropical cereals reach higher germination values at high incubation temperatures, the optimum being close to $25-30^{\circ} \mathrm{C}$, while they germinate poorly (i.e. dormancy is expressed) at lower temperatures (Simpson, 1990; Benech-Arnold et al., 2003). Dormant grains can also be very sensitive to other factors that inhibit germination, such as oxygen deprivation (Corbineau and Côme, 1980; Corbineau et al., 1981, 1986; Lenoir et al., 1983, 1986; Bradford et al., 2007, 2008), low water potential of the medium (Corbineau and Côme, 1996) and exposure to light, in particular blue light (Chaussat and Zoppolo, 1983; Gubler et al., 2008; Jacobsen et al., 2013; Barrero et al., 2014; Hoang et al., 2014).

Although dormancy is a heritable trait, its intensity at harvest and its maintenance afterwards can also be modulated by the environmental conditions throughout grain development and maturation, and during grain storage. Among the different factors acting on the mother plant, temperature appears as a major 
factor responsible for year-to-year variation in grain dormancy (and sprouting susceptibility) for plants with the same genotype. Low temperatures during grain development result in higher grain dormancy in wheat (Black et al., 1987; Nakamura et al., 2011) and barley (Rodríguez et al., 2001). The quantitative relationship between temperature during grain development and the level of dormancy soon after physiological maturity was explored in malting barley, showing that a positive linear relationship exists between the average temperature at the crop site during a precise 'thermal time window' and the germination index of grains tested $12 \mathrm{~d}$ after physiological maturity (Rodríguez et al., 2001). This predictive model was later adapted to several malting barley cultivars in Argentina and, together with local weather forecast data, provides a tool for estimating the sprouting risk for a particular crop and for making crop-management decisions (Rodríguez et al., 2001; Gualano and Benech-Arnold, 2009a). The impact of nitrogen and water availability has also been evaluated (Gualano and Benech-Arnold, 2009b). In this study, drought promoted dormancy release but the magnitude of this effect depended on the thermal conditions during the sensitivity window described above. A different result was obtained for a low-dormancy wheat (Biddulph et al., 2005), in which drought treatments during grain maturation increased dormancy and sprouting tolerance, overriding the effects of temperature. Understanding these genetics $X$ environment $(G \times E)$ interactions for different crops is important to aid breeding for adequate dormancy responses under particular environments.

After harvest, dormancy is gradually lost during dry storage at ambient temperatures. This phenomenon, usually termed 'afterripening', results in an increased germination rate at the thermal optimum and widening of the temperature range compatible with good germination (Corbineau and Côme, 1980, 1996; Corbineau et al., 1981; Côme et al., 1984). During dormancy release, grains also become less sensitive to the inhibitory effects of hypoxia (Corbineau and Côme, 1980; Bradford et al., 2007, 2008) and light (Chaussat and Zoppolo, 1983; Gubler et al., 2008; Barrero et al., 2009). Using a population-based threshold model, Bradford et al. $(2007,2008)$ have quantified the median base $\mathrm{O}_{2}$ percentage that allows $50 \%$ germination; it was estimated to be $2.27 \%$ and $0.05 \%$, respectively, for wheat grains before and after ripening, and $36.30 \%$ and $0.30 \%$, respectively, for barley grains at harvest and after 9.5 months of storage at $20^{\circ} \mathrm{C}$.

Afterripening usually occurs at ambient temperatures, but loss of dormancy can be sped up by increasing the temperature during storage (Simpson, 1990). Conversely, afterripening is slowed down and dormancy is maintained when seeds are stored dry in a freezer at $-18^{\circ} \mathrm{C}$ (Lenoir et al., 1983) and this has been a useful resource in dormancy research, providing ready accesss to dormant grains.

\section{Induction of secondary dormancy}

Primary dormancy is set during seed development, but a secondary dormancy can develop in response to conditions unfavourable for germination in mature cereal grains which retain some degree of primary dormancy (Hilhorst, 2007; Hilhorst et al., 2010). Induction of secondary dormancy by high temperature and hypoxia (e.g. produced by immersion of seeds in water) occurs in numerous cereals (Simpson, 1990), such as wheat (Grahl, 1965), barley (Leymarie et al., 2008; Hoang et al., 2013a, b) and oat (Corbineau et al., 1993; Corbineau and Côme, 2003). In barley and oat, induction of a thermodormancy is already apparent after $3-8 \mathrm{~h}$ of incubation at $30^{\circ} \mathrm{C}$, and is optimal after 1-3d (Corbineau et al., 1993; Leymarie et al., 2008). This phenomenon corresponds to a reinforcement of the primary dormancy, grains being able to germinate in a narrower temperature range than those having primary dormancy. The induction of thermodormancy requires a critical moisture content of the embryo, of about $40-50 \%$ (dry weight basis) (Corbineau and Côme, 2003; Hoang et al., 2013b), corresponding to an energy charge $[\mathrm{EC}=(\mathrm{ATP}+0.5$ $\mathrm{ADP}) /(\mathrm{ATP}+\mathrm{ADP}+\mathrm{AMP}$ )] of at least 0.6 (Corbineau and Côme, 2003), and concomitant with activation of the cell cycle (Gendreau et al., 2008; Hoang et al., 2013b). More recently, Hoang et al. (2013a, 2014) have also demonstrated that secondary dormancy can be imposed during imbibition at lower temperatures $\left(10-15^{\circ} \mathrm{C}\right)$ combined with oxygen tensions lower than $10 \%$ or under blue light, conditions that inhibit germination of seeds having primary dormancy.

\section{Anatomy of cereal seed dormancy \\ Grain structure and chemical composition of the coats}

The dispersal unit of cereals is a caryopsis, i.e. a dry monospermic indehiscent fruit, where the pericarp is fused to the outside of the true seed coat (testa) (Fig. 1). The grain comprises (1) an embryo, consisting of the embryonic axis with the coleorhiza surrounding the radicle (or embryonic roots) and the coleoptile enclosing the shoot meristem and primary leaves, and the scutellum; (2) the endosperm, differentiated into two layers consisting of the starchy endosperm and the surrounding aleurone layer, constituted by one (wheat, rye, maize, oat, sorghum) or up to three (barley) layers of thick-walled cells; (3) the seed coats (nucellus and testa) fused to the pericarp (Simpson, 1990; 


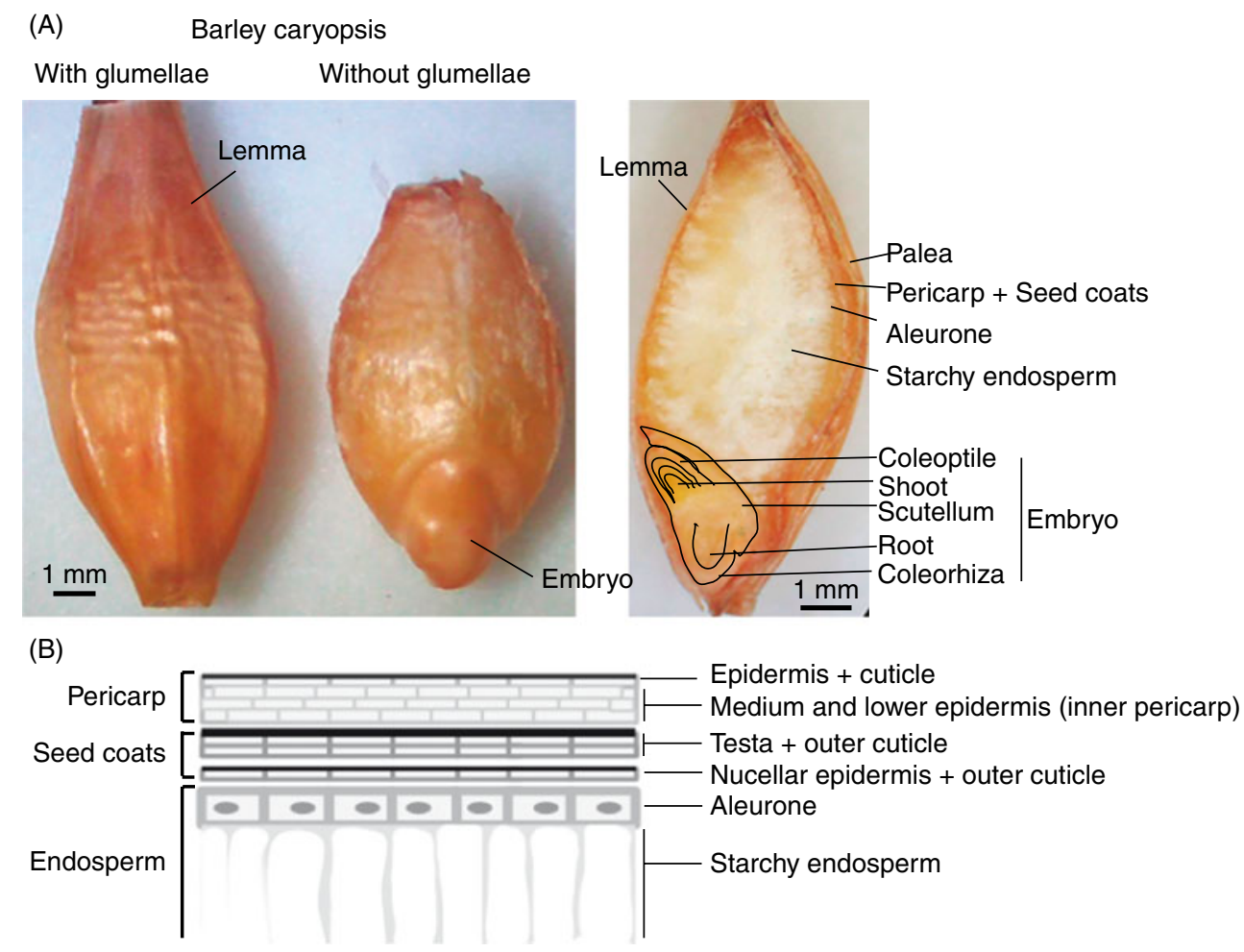

Figure 1. (A) Dorsal view of a barley grain with the hulls (glumellae) and after manual removal of the lemma and palea. On the right, a longitudinal cross-section of a barley grain indicating the main structures. (B) Schematic view of the external layers of a caryopsis, including the pericarp, the seed coats (testa plus nucellar epidermis, each with an outer cuticle) and the aleurone layer (living endosperm) above the starchy endosperm (dead cells, with amyloplasts). The number of cells for each of these layers varies among different species (see text), as does the composition and distribution of a variety of phenolic compounds with antioxidant properties, which can confer pigmentation.

Kent and Evers, 1994; Evers and Nesbitt, 2006). Endosperm and embryo are surrounded by the nucellar epidermis with a cuticle on the outer side in most cereals, and the testa with one or two cellular layers, except in some sorghum varieties where the testa is absent. An external cuticle can also be present on the outer surface of the testa in some cereals such as rice, oat and maize, regulating water absorption. The pericarp is a multilayered structure with empty dead cells, which can differentiate epidermal trichomes at the non-embryo end in wheat (brush), barley and oat. In addition, in barley, oat, rice and some sorghum genotypes, the grain is covered to different extents by the hulls (consisting of the glumellae - lemma and palea - or the glumes, depending on the species; Fig. 2) which are not removed (barley, oat), are removed with difficulty (rice), or are more or less easily (sorghum) removed by threshing. These bracts, also referred to as hulls, constitute an additional covering structure that affects water uptake and oxygen supply to the embryo, and may also supply water-soluble chemicals to the caryopsis. The presence of these bracts may vary between the intact spikelet (before harvest) and after harvest and threshing (Fig. 2); therefore, the contribution of these bracts, either to PHS tolerance or to germination of the threshed grains, has to be considered accordingly.

The external structures of cereal grains, including testa, pericarp and hulls, accumulate various phenolic compounds, such as phenolic acids (sinapic-, ferulic-, caffeic-, vanillic- and $p$-hydroxybenzoic acid), coumarins, flavonoids and tannins (Jayachandran-Nair and Sridhar, 1975; Slominski, 1980; Glennie, 1981; Collins, 1986; Lenoir et al., 1986; Weidner et al., 1993, 1999, 2000, 2002; Tian et al., 2004). The major flavonoids are flavonols, anthocyanins, deoxyflavonoids (or phlobaphenes) and proanthocyanidins (WinkelShirley, 1998, 2001; Lepiniec et al., 2006). Flavan-4-ols are the major precursors of phlobaphenes which confer a red colour in wheat, maize and rice (Grotewold et al., 1994; Himi et al., 2002), and condensation of flavan-3-ols results in synthesis of proanthocyanidins, the oxidation of which (through polyphenol oxidase activity) confers a brown colour (Winkel-Shirley, 1998). In rice, flavonoids and proanthocyanidins confer red colour to the grains (Oki et al., 2002; Sweeney et al., 2006), and accumulate only in the lower epidermal cell layer of the pericarp (Gu et al., 2011). Purple and black pigments in rice grains are also associated with the presence of anthocyanins (Reddy et al., 1995). 


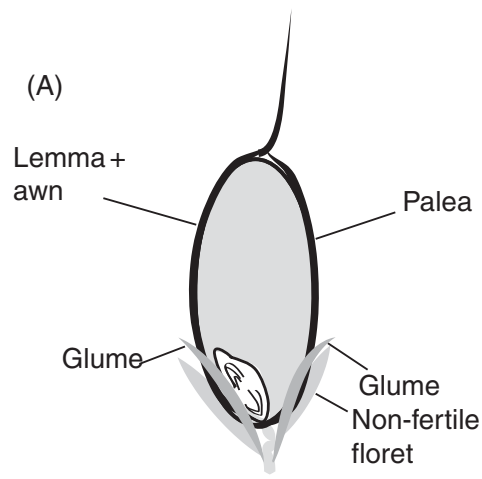

Barley
(B)

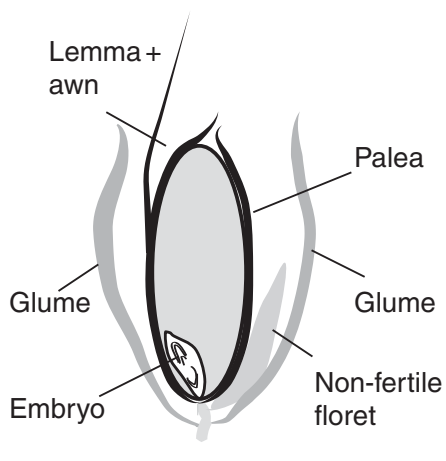

Oat
(C)

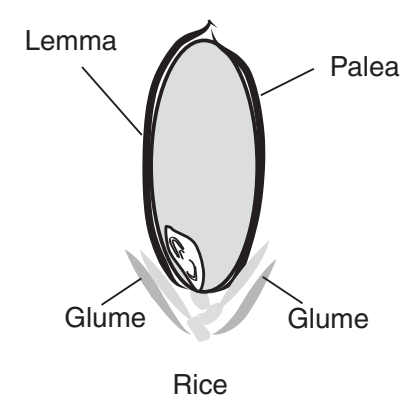

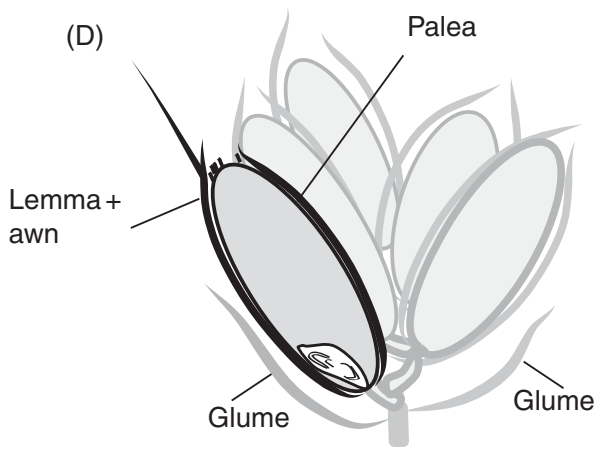

Wheat
(E)

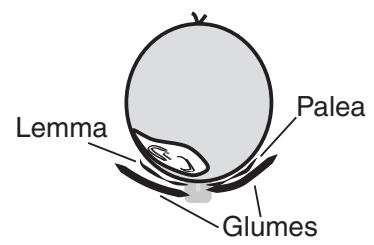

Sorghum

Figure 2. Schematic view of spikelets from different cereal species, indicating (in black) the hulls (or bracts) that may remain attached to the mature caryopsis. In both barley (A; two-row barley, one fertile floret develops into the grain) and oat (B) the caryposis is enclosed by the lemma and palea that remain in the detached grain, and these bracts are not removed by threshing. In both rice (C) and wheat (D; multiple grains in one spikelet) the lemma and palea, which are loosely attached to the mature caryopses, are usually removed mechanically during threshing. In the sorghum grain (E) both glumellae and glumes may vary greatly in size, depending on the genotype. When these bracts are short, removal is easy during harvest and threshing, but this becomes more difficult with increasing size of the glumes (which in some cases cover the entire caryopsis).

Several of the above-mentioned phenolics were tested in germination assays and found to have a strong inhibitory effect on cereal grains, including wheat, barley and sorghum (Krogmeier and Bremner, 1989). It has been proposed that some of these soluble components diffuse from the coats into the imbibing embryo and contribute to coat-based dormancy in wheat (discussed in Rathjen et al., 2009). Although phenolic compounds in the grain may perform as germination inhibitors themselves, studies that quantify their effects in vivo and in relation to dormancy are still lacking. On the other hand, it is known that these components in the hulls have a role in regulating oxygen levels in barley and oat caryopses, as will be discussed in the following section.

\section{Dormancy imposed by the seed-covering structures}

Studies performed with the main genera of cereals demonstrate that the inability of the grains to germinate at harvest is due to a complex interplay between coat- and embryo-based dormancy, with the former playing a major role in the overall contribution to grain dormancy. Removal of the covering structures, such as the hulls (glumellae or glumes) or the pericarp, testa and endosperm from the caryopsis results in a reduced expression of dormancy at a wide range of temperatures (Côme et al., 1984; Simpson, 1990; Corbineau and Côme, 1993, 1996; Steinbach et al., 1995; Benech-Arnold et al., 2003; Benech-Arnold, 2004). Nevertheless, although the naked caryopsis or the isolated embryos might appear to be non-dormant when incubated in water, different responsiveness to inhibitory factors such as abscisic acid (ABA) or hypoxia (which are speculated to be maintained by the covering structures) suggest that embryo-related factors (discussed in the section 'Hormones in the expression of dormancy in the imbibed grain' below) are also relevant in the expression of coat-imposed dormancy. An example of this contribution of the embryo to grain dormancy was provided by genetic 
studies in wheat by Flintham (2000), who identified an embryo-related factor that increases dormancy and tolerance to PHS in both red and white varieties.

The intensity of coat-based inhibition of germination depends on the species or cultivar, the environmental conditions of seed development on the ear, and the maturity stages of the grains. In barley, the glumellae have a main role in dormancy, since de-hulled grains germinate in a wide range of temperatures (Lenoir et al., 1983, 1986; Corbineau and Côme, 1996), while in oat, the glumellae together with the testa plus pericarp participate in dormancy (Corbineau et al., 1986). In barley, the presence of hulls is a desirable trait as they aid during the filtration phase in the brewing process. In naked grains, such as wheat and sorghum, the pericarp, testa and endosperm surrounding the embryo also contribute to dormancy (Corbineau et al., 1981; Steinbach et al., 1995), and dormancy has often been associated with grain colour. In temperate cereals (e.g. barley and oat), the inhibitory effect of the covering structures is very weak at low incubation temperatures $\left(5-10^{\circ} \mathrm{C}\right)$, while it increases at higher temperatures (Lenoir et al., 1983, 1986; Corbineau et al., 1981, 1986; Corbineau and Côme, 1996). This coat-imposed dormancy gradually disappears during afterripening (Côme et al., 1984).

The covering structures mainly inhibit germination by limiting oxygen supply to the embryo; although isolated embryos of dormant grains germinate fully when incubated in a 3-5\% oxygen atmosphere, the oxygen levels beneath the glumellae can drop below these values depending on incubation temperature and glumella properties. Oxygen levels within the imbibed grain decrease as a result of respiratory activity in the embryo and aleurone layer, but also due to oxidative reactions in the hulls (Lenoir et al., 1986; Corbineau and Côme, 1996; Benech-Arnold et al., 2006; Bradford et al., 2008; Hoang et al., 2013a). Recently, Hoang et al. (2013a) demonstrated that the embryo oxygen content under the glumellae, measured with micro-sensors, is very much lower at $30^{\circ} \mathrm{C}(0.3 \%)$, a temperature at which barley grain dormancy is expressed, than at $15^{\circ} \mathrm{C}(15.8 \%)$, at which grains germinate. This limitation to oxygen penetration by the covering structures is also supported by a 400 -fold greater median oxygen requirement for germination of dormant intact grains than for isolated embryos (Bradford et al., 2008).

During imbibition, the hulls act as a barrier to oxygen diffusion into the embryo since oxygen has to dissolve in the imbibed water, but glumellae also provide substrates and enzymes for oxidation reactions. In barley and oat, the glumellae fix abundant amounts of oxygen during imbibition through enzymatic oxidation of phenolic compounds by polyphenol oxidases localized in the cell walls (Corbineau et al., 1986; Lenoir et al., 1986). The efficiency of this oxygen-depleting mechanism rises with increasing temperature; at $30^{\circ} \mathrm{C}$, for example, more than $50 \%$ of the total oxygen absorbed by the grain is accounted for by the glumellae, while it does not exceed $25 \%$ at $10-15^{\circ} \mathrm{C}$ (Lenoir et al., 1983; Côme et al., 1988). There are, however, practically no qualitative or quantitative differences in phenol and polyphenol oxidase compositions between glumellae of dormant and non-dormant caryopses. Instead, the temporal pattern of oxygen uptake (but not the total amount of absorbed oxygen) has been related to the different germination response of fresh (dormant) and afterripened barley grains. Glumellae of dormant grains start to take up oxygen at the beginning of imbibition, whereas those of non-dormant grains start to take up oxygen only after about $12 \mathrm{~h}$ and maintain higher oxygen levels within the grain during early imbibition (Lenoir et al., 1983, 1986; Corbineau et al., 1986). It has been suggested that progressive and spontaneous cross-linking of substrates and/or enzymes to the cell wall during afterripening might delay their solubility upon hydration, providing a causal relationship between afterripening, changes in the timing of oxygen uptake and dormancy loss (Lenoir et al., 1983).

Phenolic compounds in the testa and/or pericarp of grains may also influence the regulation of oxygen levels in the embryo. Red-grained wheat and rice cultivars usually show a higher level of dormancy than white-grained ones (Gordon, 1979; Cohn and Hughes, 1981; Mares, 1993; Flintham, 2000), and pigmentation of the testa and dormancy are also positively related in barley grains (Himi et al., 2012). Genetic analysis has also associated colour of the pericarp with seed dormancy in weedy red rice ( $\mathrm{Gu}$ et al., 2005, 2011), wheat (Himi et al., 2002) and in the model plant species Arabidopsis thaliana, where the transparent testa mutants further support a link between testa pigmentation and dormancy (Debeaujon et al., 2000, 2001). Normal pigmentation of the testa is also necessary for normal expression of dormancy in barley: the mutant ant28 fails to accumulate proanthocyanidins in the testa and displays reduced grain dormancy (Himi et al., 2012). Through molecular cloning of barley ant28, Himi et al. (2012) showed that it encodes Tamyb10, a transcriptional regulator previously identified in wheat as the red pericarp (R-1) gene (Himi et al., 2002). Nevertheless, the physiological mechanism underlying the simultaneous regulation of pigmentation and dormancy by Tamyb10/Hvant28 is still unclear, and it might involve the accumulated pigments directly (which may either inhibit germination themselves or through the regulation of oxygen levels) or the regulation of another 'dormancy' gene by this transcription factor (Himi et al., 2012).

In addition to their role in the seed coats and hulls, phenolic components accumulated within the 
embryo might also have a role in the expression of embryo-related dormancy; an inverse correlation between the contents of free phenolic acids in developing embryos and the intensity of precocious germination occurs in triticale (Weidner et al., 2002).

\section{Hormonal regulation of dormancy}

\section{The ABA-GA antagonism regulates dormancy in the developing cereal grain}

The plant hormone abscisic acid (ABA) has a crucial role in the induction of dormancy in the developing grains of all cereal species studied so far. It plays a central role in higher plants by regulating plant growth and development, including seed maturation and dormancy, as well as adaptation to a variety of environmental stresses (Zeevaart and Creelman, 1988; Cutler et al., 2010; Nambara et al., 2010). Biochemical studies and analyses of mutants that block ABA synthesis indicate that $\mathrm{ABA}$ is synthesized by oxidative cleavage of C40 epoxy-carotenoids to produce xanthoxin, which is subsequently converted to ABA via the ABA-aldehyde intermediate (Tan et al., 1997; also reviewed in Nambara and Marion-Poll, 2003). The cleavage of 9-cis-epoxycarotenoids to xanthoxin, is catalysed by 9-cis-epoxycarotenoid dioxygenases (NCED), and is considered to be the key regulatory step of abscisic acid (ABA) biosynthesis in plants. Catabolism of ABA is also important in regulating $\mathrm{ABA}$ levels and comprises two processes: ABA hydroxylation or conjugation. However, the hydroxylation of $\mathrm{ABA}$ at the $8^{\prime}$-position to produce 8'-hydroxy ABA, which isomerizes spontaneously to phaseic acid (PA), is considered to be the predominant pathway of ABA catabolism (Nambara and MarionPoll, 2003). ABA inactivation by hydroxylation is performed by members of the CYP707A family of P450 mono-oxygenases, ABA 8'-hydroxylases. All plant species examined to date encode NCED and CYP707A as multigene families, and differential combinations of these members contribute to tissueand environment-specific regulation (reviewed in Nambara et al., 2010).

Several studies have focused on the evolution of embryonic ABA content during grain development in wheat, sorghum and barley (Walker-Simmons, 1987; Steinbach et al., 1997; Benech-Arnold et al., 1999), expecting to find less ABA in genotypes displaying an anticipated release from dormancy. However, ABA peaked at around physiological maturity and declined thereafter, and the ABA content of developing grains did not correlate with a particular time of exit from dormancy. In parallel, manipulation of ABA content produced deep changes in patterns of dormancy release. Reduction of ABA during seed development (as in mutants impaired in ABA biosynthesis, or after the application of an ABA-synthesis inhibitor) led to complete abolishment of dormancy or to a reduction of dormancy intensity. For example, maize kernels are viviparous if the ABA signal is reduced or abolished (as in $v p 5$ and $v p 1$ mutants, which are ABA deficient and ABA insensitive, respectively, or with the application of fluridone, an ABA biosynthesis inhibitor) (White and Rivin, 2000; White et al., 2000). Spraying young sorghum panicles with fluridone reduced $\mathrm{ABA}$ content in the grains and anticipated dormancy release, making a sprouting-resistant line behave as a sprouting-susceptible one (Steinbach et al., 1997). Several rice mutants exhibit vivipary and photooxidation in the light. These mutants, named phs1 to phs4, result from mutations in genes encoding phytoene desaturase, $\zeta$-carotene desaturase, carotenoid isomerase and lycopene $\beta$-cyclase, which are the major enzymes involved in the synthesis of the carotenoid precursors of ABA (Fang et al., 2008). Evidence for a central role of ABA in the expression of grain dormancy has also been provided by several non-dormant wheat mutants, which display either reduced ABA sensitivity or reduced ABA content (Kawakami et al., 1997; Rikiishi \& Maekawa, 2010; Schramm et al., 2012).

Although it became clear from these and many other experiments that manipulating $\mathrm{ABA}$ has an impact on dormancy, differences in endogenous $A B A$ content in cereal varieties do not usually appear to be linked to the observed differences in dormancy (Walker-Simmons, 1987; Steinbach et al., 1997). Instead, responsiveness of isolated embryos to exogenous $\mathrm{ABA}$ is highly correlated with dormancy expressed in the intact grains from several species, such as wheat (Walker-Simmons, 1987; Morris et al., 1989; Corbineau et al., 2000; Gerjets et al., 2010), barley (Wang et al., 1995; Benech-Arnold et al., 1999, 2006; Leymarie et al., 2008; Barrero et al., 2009), oat (Corbineau et al., 1991, 1993), sorghum (Steinbach et al., 1995) and rice (Gianinetti and Vernieri, 2007). Different embryo sensitivity to ABA can result from differential signalling activity or efficiency of molecular components of the ABA signal transduction pathway, although differential catabolism rates might also affect embryo responsiveness to exogenous ABA (Benech-Arnold et al., 2006). The first ABA signalling component identified in cereals was VIVIPAROUS-1 (VP1). Maize vp1 mutant kernels are viviparous (i.e. growth arrest is never imposed in this mutant and the embryo continues to grow), and although ABA amounts are similar to those of the wild type, mutant embryos have reduced sensitivity to ABA (Robichaud and Sussex, 1986). The VP1 gene is expressed in developing seeds, and encodes a transcriptional factor that is a key determinant of seed-specific gene expression, and regulates positively ABA signalling (McCarty et al., 1989). The orthologous 
genes for maize VP1 were also cloned in several cultivars from wheat, rice and sorghum, and several studies have attempted to relate their expression to dormancy. In two grain sorghum inbred lines with contrasting dormancy, expression of VP1 in embryos of developing grains did not differ substantially (Carrari et al., 2001). However, in wheat and rice, evidence of missplicing was obtained for genotypes displaying early dormancy release (Fan et al., 2007).

Another protein, Sdr4, is involved in the natural variability of dormancy in rice. This protein plays a key role in the establishment of dormancy, and different alleles (Sdr4- $k$ and $S d r 4-n)$ exist in Kasalath (prolonged dormancy) and Nipponbare (brief dormancy) cultivars (Sugimoto et al., 2010). Although the precise function of the Sdr4 protein remains unknown, it is clearly related to ABA signalling during seed development: not only is the expression of the Sdr4 gene up-regulated by OsVP1 transcription factor in the developing embryo, but Sdr4 protein is also necessary for ABA-mediated inhibition of germination, and sensitivity to exogenous ABA is enhanced in grains expressing the strong dormancy allele, $S d r 4-k$.

As mentioned above, red grain colour in wheat and rice, and accumulation of tannins in the testa in sorghum, are positively related to grain dormancy, at least until late maturation stages. Although ABA and flavonoid biosynthetic pathways do not share any common precursor (as do ABA and carotenoids), there are some regulatory components that connect $\mathrm{ABA}$ metabolism and/or signalling to flavonoid metabolism. As will be referred to in later sections, this functional connection between grain colour and ABA metabolism in the developing grain has been a problem for breeders seeking to improve dormancy in white-grained cereals without altering their colour. The reason for the tight linkage between these two traits in red rice has been elucidated: a gene responsible for strong dormancy was identified in weedy red rice and found to encode a transcription factor, SD7-1, that regulates several ABA synthesis genes. Normal expression of the SD7-1 allele in red rice results in a peak of ABA around $10 \mathrm{~d}$ after pollination, at the same time as it enhances the expression of genes involved in flavonoid biosynthesis and pigmentation of the pericarp (Gu et al., 2011). This finding shows that, in red rice, a single gene encoding a transcriptional regulator has pleiotropic effects on dormancy and pigmentation. Similarly, the red pericarp R-gene responsible for grain colour in red wheat (also related to PHS tolerance) encodes a Myb transcription factor (Tamyb10) that promotes dormancy and also the expression of several genes involved in the flavonoid biosynthesis pathway in developing wheat grains (Himi et al., 2002, 2005). Nevertheless, in contrast to SD7-1, no evidence regarding an effect of Tamyb10 on ABA metabolism or embryo responsiveness to this hormone has been shown in wheat (Himi et al., 2011) or barley (Himi et al., 2012) and the mechanism by which it exerts its effect on dormancy is still unknown.

It has been known for a long time that gibberellins (GA) promote germination of dormant seeds in many species, antagonizing the inhibitory effect of ABA. Both $\mathrm{ABA}$ and GA also act antagonistically in the inception of dormancy during early development. Evidence for a role of GA in early development was produced by White and co-workers (White and Rivin, 2000; White et al., 2000), who studied developing caryopses of maize mutants impaired in ABA and GA metabolism. Vivipary observed in maize kernels with reduced $\mathrm{ABA}$ content (as in the $v p-5$ mutant, or after treatment with ABA biosynthesis inhibitor) was prevented and the 'normal' dormancy phenotype restored in the vp5/d1 double mutant, impaired in both ABA and GA synthesis. These kernels also survived desiccation and were able to germinate at maturity. It can be concluded that the balance between ABA and GA action governs dormancy induction and germination response, and that if ABA signalling is reduced, then germination no longer depends on GA. Similarly, application of a GA biosynthesis inhibitor to young sorghum panicles reduced GA content during development and delayed dormancy release for several weeks in a typically short-lived dormancy line (Steinbach et al., 1997). Similar to observations on ABA in developing grains of sorghum varieties with contrasting dormancy, no correlation has been found between natural endogenous GA content and dormancy (Benech-Arnold et al., 2000).

Gibberellin signalling involves several components, including the DELLA (Asp-Glu-Leu-LeuAla) domain repressors of GA responses. When the GA hormone receptor GA-INSENSITIVE DWARF1 (GID1) binds GA, it undergoes a conformational change that allows binding to the DELLA repressor. Formation of the GID1-GA-DELLA complex leads to DELLA destruction via the ubiquitin proteasome pathway, thereby lifting DELLA repression of GA responses such as seed germination and stem elongation (reviewed by Davière and Achard, 2013). Many GA-response mutants have been described in cereals, but only a few are significantly affected in their level of dormancy. For example, the Rht (reduced height) alleles produce a GA-insensitive phenotype because the mutated DELLA protein is resistant to GID1-GA targeted degradation and constitutively represses the GA signal. This is the case for $R h t 3$, a dominant allele in an extremely dwarf wheat cultivar (Tom Thumb): the presence of the Rht3 allele inhibits premature $\alpha$-amylase production in ripening grains and enhances seed dormancy in the field (Flintham and Gale, 1982). Unlike mutations affecting VP1 and $S d r 4$, which are specific to the seed, the dominant allele Rht3 produces pleiotropic defects outside the seed, 
affecting plant height and flowering time. Besides this dominant DELLA allele, no other GA-signalling component has been related to natural variation for seed dormancy in a cereal species.

\section{Hormonal control of dormancy release}

So far, evidence supports a key role for the ABA/GA balance in the establishment of a dormancy programme during early grain development (Karssen and Lacka, 1986; White and Rivin, 2000; White et al., 2000; Finch-Savage and Leubner-Metzger, 2006). Important physiological changes take place in the grain as it approaches physiological maturity and maximum dry weight, which include programmed cell death of the starchy endosperm cells and rapid dehydration of the remaining living tissues in the embryo and the aleurone layer. After physiological maturity, dehydration proceeds until an equilibrium with ambient humidity is reached. In many cereal varieties, dormancy release begins after harvest maturity, but in others, dormancy release begins soon after physiological maturity is attained (as in several barley cultivars), or even before this (e.g. grain sorghum PHS-susceptible lines). Analysis of ABA content in the embryos of maturing grains of wheat, sorghum and barley shows a sharp decrease in ABA between physiological maturity and harvest maturity (Walker-Simmons, 1987; Steinbach et al., 1997; Benech-Arnold et al., 1999). Nevertheless, ABA content alone does not explain dormancy release in wheat and sorghum genotypes with contrasting dormancy dynamics, and embryo sensitivity to ABA decreases precociously in short-lived dormancy grains from both species (Walker-Simmons, 1987; Steinbach et al., 1997). In barley, changes in ABA content and sensitivity to ABA occur during late maturation stages, and in this case both variables correlate with dormancy loss occurring in two cultivars with contrasting timing of dormancy release (Benech-Arnold et al., 1999). Again, ABA appears as the key regulator of the observed patterns of dormancy release.

Although dormancy loss may begin soon after physiological maturity in some cereal varieties, others maintain high dormancy until harvest, and dormancy release takes place in the mature, dry grain as part of the afterripening process. Dry afterripening is generally effective at a seed moisture content between 5 and $18 \%$ fresh weight basis, but it can be prevented at very low moisture contents (Bazin et al., 2011) or by low temperatures $\left(-18^{\circ} \mathrm{C}\right)$. Transcriptional analysis of dormant (freshly harvested) and dry afterripened (non-dormant) wheat grains shows no significant changes in hormone-related transcripts (A. Liu et al., 2013; Chitnis et al., 2014), suggesting that changes in the transcription of hormone-related genes during dry storage are less likely to be an integral part of mechanisms underlying dormancy decay by afterripening. Endogenous hormone concentrations [ABA, jasmonic acid and indole-acetic acid (IAA)] also remain unchanged during dry afterripening of wheat grains (A. Liu et al., 2013). Additional studies with seeds from other species also support the observation that no relevant transcriptional changes take place during dry afterripening that can account for changes in dormancy (Meimoun et al., 2014). In anhydrobiotic conditions of afterripening, non-enzymatic mechanisms are good candidates for playing a role in dormancy release. Oxidation of proteins and transcripts was studied in sunflower during seed dormancy release by Oracz et al. (2007) and Bazin et al. (2011). They observed that within the existing pool of mRNA stored in the mature grain a subset of transcripts was oxidized. Some of the identified transcripts were related to known ABA-signalling components, such as PP2C, MPK1 and ABC-2-type transporter, a putative ABA cellular transporter (Bazin et al., 2011). This non-enzymatic mechanism may account for changes in ABA responsiveness observed during afterripening in cereal species, and future studies will hopefully shed some light on this possibility.

\section{Hormones in the expression of dormancy in the imbibed grain}

Soon after water uptake occurs and the embryo becomes imbibed, cell metabolism is activated and germination begins in a non-dormant seed. Although metabolism is also activated in a dormant, imbibed seed, the completion of germination remains blocked and enzymatic activity leading to embryo growth and reserve mobilization does not proceed because of repression by ABA. Embryos from dormant barley grains are able to synthesize and maintain a high ABA content upon imbibition under conditions at which dormancy is expressed, while in embryos from nondormant grains this ABA is rapidly depleted (BenechArnold et al., 2006; Millar et al., 2006). Hormone content is the result of two processes: synthesis and catabolism. A reduction in ABA content in embryos of non-dormant grains, or in those incubated under conditions at which dormancy is not expressed, can be due to a slow, or even repressed, biosynthesis; an increased inactivation rate; or to the co-ordinated action of both.

In barley, the rapid decline in ABA content observed in imbibing non-dormant (afterripened) grains is likely to be due to increased expression of $H v A B A 8^{\prime} O H 1$, a gene encoding an ABA catabolic enzyme, while it is not clearly related to the expression of HvNCEDs and other ABA biosynthesis genes 
(Millar et al., 2006; Barrero et al., 2009). In addition to these changes in ABA metabolism, changes in ABAsignalling genes are also involved in dormancy release by afterripening (Benech-Arnold et al., 2006; Millar et al., 2006; Gubler et al., 2008; Barrero et al., 2009).

Both hormonal and transcriptional analyses related to ABA metabolism were first carried out in wholeembryo samples (Millar et al., 2006), but more recently the major role of $\mathrm{ABA}$ (and the regulation of its metabolism) in dormancy was localized to the coleorhiza (Barrero et al., 2009). The coleorhiza is a non-vascularized multicellular embryonic tissue that covers the seminal roots of grass seeds, and elongates in the early stages of imbibition before root emergence (Barrero et al., 2009). Transcriptomic and hormonaltissue-specific analysis of the barley grain has shown that the coleorhiza plays a major role in causing dormancy by acting as a barrier to root emergence, and that afterripening potentiates molecular changes related to ABA metabolism and sensitivity, light responses and the jasmonate biosynthetic pathway in the coleorhiza cells (Barrero et al., 2009). Afterripening promotes $\mathrm{ABA}$ catabolism in the coleorhiza upon imbibition and also reduces sensitivity to ABA, and this is associated with differential regulation of $A B A 8^{\prime} O H 1$ and of the HvLPP gene family and $H v A I P 2$, respectively. Both HvLPP (Lipid Phosphate Phosphatase) and HvAIP2 are negative regulators of the ABA signalling pathway (Zhang et al., 2005), and are induced in imbibed, afterripened barley grains.

Very little is known about upstream regulation of ABA metabolism associated with dormancy release in cereal grains, but recent evidence from wheat indicates that jasmonates have a role in vivo in co-ordinating ABA synthesis and catabolism in the embryos. Application of methyl jasmonate reduces dormancy and ABA content in imbibed wheat grains and this is mediated via a reduction in TaNCED1 and an increase in $\mathrm{TaABA} 8^{\prime} \mathrm{OH}-1$ expression (Jacobsen et al., 2013).

While maintenance of high ABA concentrations after imbibition is required for the expression of dormancy in the barley grain, this is not the case in some wheat and sorghum genotypes (Rodríguez et al., 2009; A. Liu et al., 2013). In grain sorghum (S. bicolor), coat-imposed dormancy in two inbred lines with contrasting dormancy is not related to ABA content, which decreases similarly upon grain imbibition (Gualano et al., 2007; Rodríguez et al., 2009). In immature grains of both sorghum lines, embryo sensitivity to ABA shows a strong correlation with grain dormancy, and transcript abundance of ABA signalling genes (such as SbABI3, SbABI4, SbABI5 and $S b P K A B A)$ is induced during imbibition in the dormant line as compared to the non-dormant one. Analysis of GA metabolism genes and hormone content in these same sorghum lines (Rodríguez et al., 2012) revealed that, in the non-dormant line, $\mathrm{GA}_{4}$ content increased during imbibition and before completion of germination, and this was related to a reduced expression of a GA 2-oxidase gene (SbGA2ox3) and lower content of $\mathrm{GA}_{34}$ (the inactive catabolite produced by oxidation of $\mathrm{GA}_{4}$ ) as compared to the more dormant genotype. A possible interaction between transcription factors belonging to the $\mathrm{ABA}$ signalling pathway (i.e. ABI4, ABI5) in the promotion of GA catabolism was tested recently in vitro for the sorghum gene SbGA2ox3. Both SbABI4 and SbABI5 proteins are able to bind to conserved ABA-response elements (ABREs) within a region of the SbGA2ox3 promoter. This possible regulation of GA catabolism through components of the ABA signalling pathway appears to be restricted to a functional sub-group (M3) of GA 2-oxidases existing only in the monocots (Cantoro et al., 2013). When ABA signalling begins to decline (as in PHS-susceptible sorghum line RedlandB2 approaching physiological maturity), GA amounts increase upon imbibition and favour the ABA/GA balance towards germination, thus producing a less-dormant phenotype.

During imbibition, sensitivity to GA synthesis inhibitors added to the incubation medium is strongest, further supporting the idea that GA metabolism can make a difference in the outcome of the hormonal balance. However, once sensitivity to $\mathrm{ABA}$ is low enough, germination no longer relies on GA de novo synthesis, as inferred from the lack of response to biosynthesis inhibitors in sorghum (Rodríguez et al., 2012), but also from transcriptional evidence in barley (Barrero et al., 2009). Changes in global gene expression and hormone content were also assessed during incubation of dormant (freshly harvested) and non-dormant (afterripened) wheat grains (A. Liu et al., 2013). ABA in whole wheat grains changed similarly during imbibition for both dormant and afterripened grains, while transcriptional data supported a decreased ABA signalling and an enhanced GA synthesis in the non-dormant grains.

The functional relationship between the hulls, oxygen availability, hormones and the expression of dormancy has been investigated in barley and oat. In these species, the glumellae impose dormancy by limiting oxygen diffusion into the imbibed embryo, and increases in glumella permeability to oxygen and embryo sensitivity to oxygen during afterripening contribute then to the improvement of germination. Also, embryos isolated from non-dormant grains germinate faster and are less sensitive to hypoxia than embryos isolated from dormant ones (Corbineau and Côme, 1996, 2000; Bradford et al., 2008). Oxygen availability to the embryo, regulated by the hull, could have additional effects on the synthesis of, and sensitivity to, ABA and GA, altering their balance of potential action to either promote or retard germination (Finch-Savage and Leubner-Metzger, 2006; 
Bradford et al., 2008). In both barley and oat, the glumellae play a role in metabolic regulation of the embryo (Lecat et al., 1992; Corbineau and Côme, 2003) but also affect hormone content, in particular by preventing leaching of ABA into the medium (Wang et al., 1998; Jacobsen et al., 2002) or by interfering with ABA metabolism (Benech-Arnold et al., 2006; Mendiondo et al., 2010). Oxygen absorption by the glumellae during the first $12-14 \mathrm{~h}$ after beginning of imbibition of dormant barley grains (Lenoir et al., 1986) appears to be related to ABA metabolism in the embryo, as a transient increase in ABA content occurs within this period in dormant grains but not in afterripened ones (Benech-Arnold et al., 2006). Removal of the glumellae from barley grains suppresses this initial increase in embryo ABA content during the first hours of imbibition, but this pattern can be restored by incubating naked grains (i.e. without glunellae) under hypoxia, which also blocks germination (Benech-Arnold et al., 2006). In addition to a possible role of oxygen as a limiting substrate in ABA catabolism mediated by $\mathrm{ABA} 8^{\prime} \mathrm{OH}$ in the embryo, an oxygen-sensing mechanism such as the $\mathrm{N}$-end rule pathway could be involved in the control of germination in cereal grains, as has been described in Arabidopsis (Holman et al., 2009; Gibbs et al., 2011). The presence of the glumellae alters the expression of genes involved in ABA synthesis (HvNCED1 and HvNCED2), ABA catabolism $\left(H v A B A 8^{\prime} O H 1\right)$ and signalling $(H v A B I 5, H v V P 1$ and $H v P K A B A$ ) with respect to de-hulled grains, but curiously this effect cannot be mimicked by artificially imposed hypoxia (Mendiondo et al., 2010), suggesting that the effect of the glumellae is not limited to oxygen deprivation. Moreover, although the hypoxia imposed by the glumellae increases the responsiveness of the embryo to ABA (both directly and through an altered ABA metabolism) and reduces its sensitivity to GA, other factors related to the presence of the glumellae are likely to exist that contribute to regulate hormone action in the embryo (Benech-Arnold et al., 2006; Bradford et al., 2008; Mendiondo et al., 2010). Future studies will help us to understand better the complex interrelationships between the oxygen availability to the embryo as regulated by the covering structures, and hormone metabolism and signalling, and their changes during dormancy expression and germination.

\section{Integration of environmental signals through hormone action}

Environmental conditions, for example soil moisture and temperature, oxygen availability, and light, regulate seed germination, dormant grains being more sensitive to external factors than non-dormant ones (see the Introduction). These environmental signals are integrated through hormone metabolism and signalling, the $\mathrm{ABA} / \mathrm{GA}$ ratio having been proposed as the central component of this regulatory network (Karssen and Lacka, 1986; Finch-Savage and Leubner-Metzger, 2006).

\section{Water}

Grain imbibition is associated with changes in ABA and GA content of the embryo, which depend on the cultivar and dormancy depth (see above). The expression of dormancy in barley and oat grains is associated with maintenance of a higher ABA content, while embryo ABA decreases sharply in non-dormant grains or dormant ones placed in conditions that do not allow expression of dormancy (Ried and WalkerSimmons, 1990; Wang et al., 1995; Jacobsen et al., 2002; Benech-Arnold et al., 2006; Millar et al., 2006; Leymarie et al., 2008; Hoang et al., 2013b). However, ABA metabolism is also modulated by grain moisture content. In barley, partial hydration of the grains at a moisture content lower than $0.40-0.45 \mathrm{~g} \mathrm{H}_{2} \mathrm{O}$ (g dry weight $)^{-1}$ (which does not allow germination of either dormant or non-dormant grains) correlates with a maintenance of ABA content close to its initial value (Gendreau et al., 2008; Hoang et al., 2013b). Expression of genes involved in ABA and GA metabolism is water dependent; that of $H v A B A 8^{\prime} O H 1, H v N C E D 1$ and HvNCED2 (involved in ABA metabolism) and of $H v G A 2 o x 1, H v G A 2 o x 3$ and $H v G A 2 o x 5$ (involved in GA catabolism) are not affected at moisture content as low as $0.40-0.45 \mathrm{~g} \mathrm{H}_{2} \mathrm{O}$ ( $\mathrm{g}$ dry weight $)^{-1}$, when transcript abundance of HvGA3ox2, HvGA20ox1 and HvGA20ox3, involved in GA synthesis, is about twofold higher than in dry grains (Hoang et al., 2013b).

\section{Temperature}

Responsiveness of dormant grains to temperature is strongly correlated with depth of dormancy. In temperate cereals (e.g. wheat, oat and barley) incubation at high temperatures (which enhance dormancy expression) results in the maintenance of high ABA concentrations in the embryo (BenechArnold et al., 2006; Leymarie et al., 2008; Hoang et al., 2013b). High incubation temperatures can inhibit germination of barley grains with primary dormancy, but can also induce secondary dormancy, which is evidenced after transfer to non-inhibitory conditions (e.g. $15^{\circ} \mathrm{C}$ for barley). Grains showing both primary and secondary dormancy display higher ABA contents during imbibition as compared to non-dormant grains (Hoang et al., 2013b). While the maintenance of higher ABA content during the expression of primary dormancy at $30^{\circ} \mathrm{C}$ is mainly correlated with reduced 


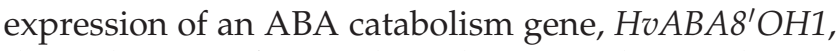
the induction of secondary dormancy by incubation at $30^{\circ} \mathrm{C}$ is associated with an increase in the expression of ABA biosynthesis genes HvNCED1 and HvNCED2 (Hoang et al., 2013b). In contrast, the decrease in ABA content observed at low incubation temperatures (at which primary dormancy is not expressed) is associated with an increase in $\mathrm{HvABA} 8^{\prime} \mathrm{OH} 1$ transcript abundance, but with no significant change in the expression of HvNCED1 and HvNCED2, suggesting a key role of ABA catabolism (Leymarie et al., 2008; Hoang et al., 2013b). In parallel, exposure of imbibed barley grains to high temperatures that induce secondary dormancy, also affect the relative expression of genes involved in GA synthesis and catabolism. In particular, expression of $H v G A 3 o x 2$, a gene involved in GA biosynthesis, is stronger at $15^{\circ} \mathrm{C}$ than at $30^{\circ} \mathrm{C}$, while expression of $H v G A 2 o x 3$, a gene involved in GA catabolism, is enhanced at $30^{\circ} \mathrm{C}$ as compared to at $15^{\circ} \mathrm{C}$ (Hoang et al., 2013b). In consequence, the HvGA3ox2/ $H v G A 20 x 3$ transcript abundance ratio is higher at $15^{\circ} \mathrm{C}$ (8.8) than at $30^{\circ} \mathrm{C}(0.32)$ in grains with primary dormancy, and remains low at $15^{\circ} \mathrm{C}$ in grains with secondary dormancy.

Incubation at high temperature also results in an increase in embryo sensitivity to ABA (WalkerSimmons, 1988; Corbineau et al., 1991, 1993; BenechArnold et al., 2006; Leymarie et al., 2008). In contrast, in sorghum (a summer crop, dormancy expression being promoted at lower temperatures), the improvement of germination at high temperatures cannot be explained by changes in either embryo ABA sensitivity or ABA content (Benech-Arnold et al., 2003).

Recent genetic evidence has identified the wheat homologue of MOTHER OF FT and TF1 (TaMFT) as a key regulator of germination temperature responses in dormant wheat (Nakamura et al., 2011). Low maturation (dormancy promoting) temperatures result in higher expression of TaMFT in the embryo at maturity. It is interesting to note that, in contrast to the role of TaMFT in wheat grains, AtMFT is a negative regulator of $\mathrm{ABA}$ sensitivity during Arabidopsis seed germination (Xi et al., 2010).

\section{Oxygen}

Hypoxia imposed on the embryo results in changes in the expression of various genes involved in $\mathrm{ABA}$ and GA metabolism and affects the embryo sensitivity to these hormones (Benech-Arnold et al., 2006; Bradford et al., 2008; Mendiondo et al., 2010; Hoang et al., 2013a). During imbibition, embryo ABA content decreases more slowly in hypoxia than in air either at 15 or $30^{\circ} \mathrm{C}$, but this maintenance of $\mathrm{ABA}$ content is not associated

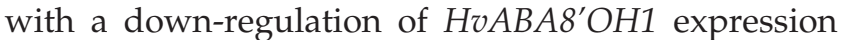
(Mendiondo et al., 2010; Hoang et al., 2013a). At $30^{\circ} \mathrm{C}$, hypoxia (with a maximum effect at $3-5 \%$ oxygen) induces the expression of $H v A B A 8^{\prime} \mathrm{OH} 1$ at least during the first $14 \mathrm{~h}$ of imbibition (Mendiondo et al., 2010), while at $15^{\circ} \mathrm{C}$, it does not affect the expression of $\mathrm{ABA}$ metabolism genes after the first day (Hoang et al., 2013a). Expression of GA metabolism genes is strongly regulated by hypoxia after $1 \mathrm{~d}$ at $15^{\circ} \mathrm{C}$, with a strong promotion of HvGA2ox3 (64-fold compared with grains incubated in air) and inhibition of $H v G A 3 o x 2$ and HvGA20ox1, suggesting that hypoxia reduces GA content (Hoang et al., 2013a).

In addition, embryo sensitivity to ABA increases by several orders of magnitude in hypoxia and seeds become unresponsive to GA at low oxygen (BenechArnold et al., 2006; Bradford et al., 2008). At $20^{\circ} \mathrm{C}$, for example, GA sensitivity of barley grains decreases by six orders of magnitude between $21 \%$ and $10 \%$ oxygen (Bradford et al., 2008).

\section{Light}

The inhibitory action of white or blue light on the germination of barley and wheat grains is associated with an increase in embryo ABA content, resulting in an up-regulation of NCED1 and NCED2 and a downregulation of $A B A 8^{\prime} O H-1$ (Jacobsen et al., 2002, 2013; Gubler et al., 2008; Hoang et al., 2014), and with an increase in embryo sensitivity to ABA (Hoang et al., 2014). In barley, blue light also inhibits the expression of HvGA3ox2, improves that of HvGA2ox3 and HvGA2ox5, leading to reduced GA content and signalling (Gubler et al., 2008; Hoang et al., 2014). As in Arabidopsis (Seo et al., 2006), the down-regulation of $H v G A 3 o x 2$ by blue light might result from the increase in ABA content. Results obtained by Barrero et al. (2014) using transgenic lines down-regulating genes encoding the blue light receptor cryptochrome (HvCRY1 and HvCRY2), and the partial reversion of the inhibitory effect of blue light by green light (Hoang et al., 2014), demonstrate that the hormonal regulation by blue light is mediated by cryptochrome CRY1 photoreceptor. The blue light response has been suggested to play a significant ecophysiological role, mediating germination responses based on the extent of exposure of the grain to light (Barrero et al., 2012). Grains that are on the surface of the soil will be exposed to more blue light and thus are less likely to germinate than those that are buried deeper in the soil.

So far the evidence indicates that only members of the grass family respond to the blue portion of the spectrum in germination assays. This is in contrast to dicot species, for which there is strong evidence for phytochrome-mediated regulation of germination, and blue light appears to have no effects on imbibing seeds (Barrero et al., 2014) or are restricted to imbibition conditions during which dormancy is 
strongly expressed, as reported for lettuce (Small et al., 1979). In a recent study of the wild grass Brachypodium distachyon, red-far red reversibility of germination of dormant grains was demonstrated, indicating that phytochrome B control of germination exists in a grass that is closely related to the cereals (Barrero et al., 2012). It has been speculated that red and far red effects have been selected against during domestication of cereals to improve uniformity of germination.

\section{Practical implications of knowledge about dormancy in cereals}

\section{Pre-harvest sprouting in cereals}

Dormancy is an important agronomic trait for many cereal crop species and a number of molecular strategies are now being pursued to manipulate the expression of dormancy to protect grain quality and yield. In cereal-growing regions of the world where there is a high probability of rain at harvest time, PHS is a major constraint to the production of high-quality grains (Derera, 1989; Gubler et al., 2005; Black et al., 2006; Kulwal et al., 2010). PHS can be a serious agronomical problem in temperate or tropical areas (Meredith and Pomeranz, 1985), for wheat (King, 1983), rice (Maruyama, 1980; Juliano and Chang, 1987), maize (Neill et al., 1987) and sorghum (Clark et al., 1967; Maiti et al., 1985), depending on the weather conditions. The problem is present in all major winter cereal crops, such as wheat, where it is estimated to cause losses of up to US\$1 billion worldwide (Black et al., 2006) and it is also a serious problem in tropical and subtropical crops, such as rice and sorghum. It is routinely associated with two phenotypes in the harvested grains: high $\alpha$-amylase activity (generally measured by falling number) and the presence of sprouted grains (Mares, 1989). Following rain, germination is initiated rapidly in PHS-susceptible grains, triggering expression of aleurone hydrolytic enzymes such as $\alpha$-amylases and proteases, which then, in turn, degrade the stored starch and protein reserves in the starchy endosperm. Once endosperm degradation is initiated, then the usefulness of the grains for commercial processes, such as bread and beer making, declines rapidly. Grains with severe PHS damage often are downgraded to animal feed, resulting in major losses in revenue to farmers. Ultimately the sprouting damage can lead to loss of longevity or grain viability following grain desiccation after harvest (Gualano et al., 2014). It is now clear from mapping of PHS susceptibility and dormancy quantitative trait loci (QTLs) that many genes co-locate to the same chromosomal regions, providing strong support for the contention that the prevalence of PHS in cereals is predominantly due to the lack of dormancy at harvest ripeness (Anderson et al., 1993; Mares and Mrva, 2001; Ogbonnaya et al., 2008). Earlier studies suggesting that ear morphology and composition also impact PHS remain to be confirmed (King, 1989). It is now recognized that moderate to high levels of grain dormancy are required for protection against PHS, but in certain instances this may cause problems for some downstream applications. In the case of malting barley, rapid and uniform germination is required for the production of high-quality malts (Hicky et al., 2012; Edney et al., 2013). Barley grains that retain any residual dormancy at harvest will need to be afterripened to eliminate dormancy before malting, resulting in extra storage costs.

Due to the worldwide prevalence of PHS in cereals there has been considerable research and breeding effort directed towards identifying genetic solutions to increase dormancy in grains at maturity. In breeding operations, grain dormancy is typically measured by germination tests of harvest-ripe grain, and is generally restricted to advanced lines late in the breeding cycle due to the time-consuming nature of the phenotypic screen. Marker-assisted selection of desirable dormancy genes will overcome this bottleneck and provide a strategy for early generation selection to enrich advanced generations with a suitable combination of dormancy alleles.

Genetic analysis of grain dormancy of cereals reveals that it is a complex trait controlled by multiple genes that are spread across multiple chromosomal locations. Genomic tools such as QTL mapping in combination with map-based cloning have been used with success in both rice and wheat, to discover novel genes/alleles that can be used by breeders for markerassisted introgression. Recently, other approaches, such as genome-wide-association studies, have been used to identify DNA markers linked to highdormancy alleles (Jaiswal et al., 2012; Kuwal et al., 2012; Rehman Arif et al., 2012; Rathi et al., 2014). Similarly transformation and mutation breeding also offer considerable promise as strategies to eliminate PHS in cereals. The next section will focus on the progress towards eliminating PHS in wheat and rice.

\section{Molecular breeding strategies to eliminate PHS in wheat and rice}

Many QTL studies have been performed in rice and wheat to identify chromosomal regions that contribute to natural variation in dormancy. In general, the strategy used has been to develop biparental populations derived from parental cultivars that differ in dormancy, and in some cases recombinant inbred lines have also been developed to assist with the mapping. In rice, many dormancy-related QTLs have been identified with prominent QTLs located on 
chromosome 3 (Sdr1), chromosome 12 (qSD12) and chromosome 7 (Sdr4) (Lin et al., 1998; Takeuchi et al., 2003; Gu et al., 2004; Gao et al., 2008; Hori et al., 2010; Lu et al., 2011; Wang et al., 2014). Similarly, in wheat many QTLs have been identified, with the major ones located on chromosome 4A (Kato et al., 2001; Mares and Mrva, 2001; Flintham et al., 2002; Mares et al., 2005; Mori et al., 2005; Chen et al., 2008; Torada et al., 2008; Singh et al., 2010; Kuwal et al., 2012) and group 3 chromosomes (Groos et al., 2002; Osa et al., 2003; Kulwal et al., 2005; Mori et al., 2005; Imtiaz et al., 2008; Liu et al., 2008; Fofana et al., 2009; Kumar et al., 2009; Mares et al., 2009; S. Liu et al., 2013).

The Sdr4 QTL in rice is a major contributor to dormancy in indica cultivars (Lin et al., 1998). Molecular cloning of the Sdr4 allele from japonica and indica cultivars shows that it encodes a novel nuclear protein of unknown function that is under the control of OsVP1 (Sugimoto et al., 2010). The dormant indica allele identified in Kasalath rice appears to be widely distributed in the indica group and in a wild rice ancestor Oryza rufipogon. Interestingly, analysis of the Ossdr4 mutant revealed that several germination-related genes, such as OsGA20ox-1, are down-regulated in the mutant grains compared to wild type. Isolation of TaSdr4 orthologues on the wheat chromosome 2A, B and D genomes revealed allelic variants for TaSdr-B1 ( $a$ and $b$ ) between high- and lowdormancy Chinese wheat lines (Zhang et al., 2014). Linkage and association mapping of the alleles showed high correlation of the TaSdr1-B1b allele with low-dormancy trait compared to the TaSdr-B1a allele. Analysis of the geographic distribution of the TaSdr-B1a allele revealed that it was present in higher frequencies in Chinese, Japanese, Australian and Argentine cultivars from PHS-susceptible regions, but not European cultivars.

Compared to rice, map-based cloning of candidate genes in wheat is far more difficult because of its hexaploid genome and the absence of a quality genome sequence. The major QTL for grain dormancy in wheat, which is on chromosome $4 \mathrm{AL}$, explains up to $40 \%$ of the phenotypic variability in some populations. The gene underlying the QTL has not been identified but it is thought to be syntenic with the barley SD2 dormancy QTL (Li et al., 2003) on chromosome 5HL (Flintham et al., 2002; Zhang et al., 2008). The cloning of this major QTL will be an important step in providing wheat and barley breeders with new opportunities to increase dormancy in new cultivars. Progress has been made largely through the candidate gene approach, such as that described above for TaSdr. The discovery that TaMFT has a role in mediating the effect of temperature on dormancy acquisition during grain development led researchers to investigate whether allelic variation may be responsible for dormancy differences in two wheat cultivars that show differential germination profiles when grown at low temperatures (Nakamura et al., 2011). Lowresolution mapping in recombinant inbred lines generated between the highly dormant Zen cultivar and the less dormant Chinese Spring cultivar indicates that TaMFT is located in a QTL region on chromosome 3A. Analysis of TaMFT expression identified differences in expression of the two parental alleles during grain development, with the Zen allele being more highly expressed than the Chinese Spring allele during the latter stages of grain maturation. These results are consistent with evidence from functional testing in wheat embryos, which shows that increased TaMFT expression is associated with increased dormancy. It is speculated that the differential expression between the two alleles is due to single nucleotide polymorphisms (SNPs) in the TaMFT promoter sequences, which may affect a bZIP binding site. The earlier finding is supported by fine mapping of a QTL on chromosome 3AS (Qphs.pseru-3AS) in a population derived from a PHS-resistant wheat cultivar (Rio Blanco) and PHSsusceptible cultivar NW97S186 (S. Liu et al., 2013). Physical mapping using a minimum bacterial artificial chromosome (BAC) tiling path narrowed the QTL region to a 201-kb contig which contains six genes, including TaMFT which, based on gene expression profiles in imbibed grains, is proposed to be the most likely candidate gene. Functional proof was provided by showing that RNA interference (RNAi) suppression of TaMFT results in increased germination of grain in sprouting assays. Molecular analysis of the alleles showed that increased PHS susceptibility associated with the NW97A186 allele is due to SNPs that cause mis-splicing of the gene, resulting in a loss of the functional allele. The discovery of multiple haplotypes of the TaMFT gene provides breeders with a choice of alleles to breed for PHS resistance.

As described above, red-grained wheat and rice usually show higher PHS resistance than whitegrained cultivars (Cohn and Hughes, 1981; Flintham, 2000). The association between pericarp colour and dormancy in wheat has provided breeders with an easy phenotypic screen to select cultivars that have higher dormancy. The selection for dormant red-grained cultivars has been particularly strong in wheat-growing regions of North America, Europe and China, but other countries such as Australia have preferred to select for white-grained wheats with moderate dormancy. In mapping populations between white- and red-grained wheat cultivars, the grain colour is controlled by dominant $R-1$ genes encoded by Tamyb10 located on chromosomes 3AL, 3BL and 3DL (Himi and Noda, 2005; Himi et al., 2011). Analysis of white and red grains suggests that the Tamyb10 gene regulates the early steps in the flavonoid biosynthetic pathway in the coat during grain development. However, it is important to note that the linkage 
between red-grained wheats and dormancy is not tight, since it has been found that the expression of the $R-1$ genes on their own are not sufficient to provide dormancy but requires epistatic interactions with other dormancy QTLs (Mares et al., 2005). Analysis of white mutants of red-grained wheats indicates that the red gene contribution to dormancy is small but significant (Warner et al., 2000; Himi et al., 2002).

In contrast to wheat, there has been strong selection against the red pericarp colour during rice domestication, due to visual and flavour characteristics associated with the red pigments (Sweeney et al., 2007). Genetic analysis has identified two loci that control red grain colour in rice, with one locus encoding a basic helix-loop-helix transcription factor that results in increased dormancy when introduced in white-grained rice (Sweeney et al., 2006; Gu et al., 2011).

In parallel to traditional breeding efforts to increase dormancy, molecular strategies such as transgenic, forward and reverse genetic approaches have also been used to develop new wheat germplasm with increased dormancy. However, the difficulty in mutagenic screens in wheat is compounded by the presence of three genomes, thus often requiring recessive mutations in two or three homeologous genes to reveal a phenotype. Dominant mutations only require an alteration in one of the homeologous genes to generate a phentoype. One successful approach using these methods has been to manipulate ABA catabolism and signalling in wheat grains to increase dormancy. A double mutant carrying a deletion in the $A B A 8^{\prime}$ hydroxylase-1 gene in the A genome and an insertion the homeologous gene in the D genome results in reduced ABA catabolism and increased dormancy compared to wild-type grains (Chono et al., 2013). Further work will be required to assess the performance of the double mutant lines exposed to abiotic stresses under field conditions (Ji et al., 2011). Mis-splicing of the wheat Viviparous-1 ( $\mathrm{TaVp} 1$ ) transcription factor involved in ABA signalling has been suggested as a contributor to PHS susceptibility in wheat (McKibbin et al., 2002; Wilkinson et al., 2005). To overcome this putative defect, VP1 genes from wild oats (McKibbin et al., 2002) and maize (Huang et al., 2012) have been over-expressed in transgenic wheat, resulting in increased dormancy and PHS resistance. Identification of further targets for manipulation have been found by identifying wheat genes that are orthologous to characterized dormancy genes in other plants. The demonstration that overexpression of wheat Delay of Germination 1 in transgenic wheat grains increases dormancy opens up new avenues to prevent PHS (Ashkawa et al., 2014). A novel transgenic strategy to enhance ABA biosynthesis using positive feedback has been proposed as an alternative solution to PHS in cereals (Nonogaki et al., 2014). The strategy, which has been demonstrated in a model plant, is based on the expression of a chimeric gene consisting of an ABA-responsive promoter fused to an ABA biosynthetic gene that is predicted to result in a large increase in ABA content in the cereal grain.

Forward mutant screens have been performed in wheat cultivars to identify mutants with increased dormancy (Kobayashi et al., 2008; Schramm et al., 2010, 2013). Germination screens with mutagenized white grains that have been afterripened for 6 months identified three ABA hypersensitive mutants (Schramm et al., 2013). All three lines with increased sensitivity to ABA have higher grain dormancy. The hypersensitive mutants display a slower loss of dormancy during afterripening compared to wild-type grains but, interestingly, the increased sensitivity to ABA is still present in fully afterripened grains. One mutant was identified as being particularly useful in breeding for PHS resistance in white wheat varieties, and molecular markers linked to the mutant allele will be developed to assist this strategy.

\section{References}

Anderson, J.A., Sorells, M.E. and Tanksley, S.D. (1993) RFLP analysis of genomic regions associated with resistance to pre-harvest sprouting in wheat. Crop Science 33, 453-459.

Ashkawa, I., Mori, M., Nakamura, S. and Abe, F. (2014) A transgenic approach to controlling wheat seed dormancy level by using Triticeae DOG-1-like genes. Transgenic Research 23, 621-629.

Barrero, J.M., Talbot, M.J., White, R.G., Jacobsen, J.V. and Gubler, F. (2009) Anatomical and transcriptomic studies of the coleorhiza reveal the importance of this tissue in regulating dormancy in barley. Plant Physiology 150, 1006-1021.

Barrero, J.M., Jacobsen, J.V., Talbot, M.J., White, R.G., Swain, S.M., Garvin, D.F. and Gubler, F. (2012) Grain dormancy and light quality effects on germination in the grass Brachypodium distachyon. New Phytologist 193, 376-386.

Barrero, J.M., Downie, A.B., Xu, Q. and Gubler, F. (2014) A role for barley CRYPTOCHROME1 in light regulation of grain dormancy and germination. The Plant Cell 26, 1094-1104.

Bazin, J., Langlade, N., Vincourt, P., Arribat, S., Balzergue, S., El-Maarouf-Bouteau, H. and Bailly, C. (2011) Targeted mRNA oxidation regulates sunflower seed dormancy alleviation during dry after-ripening. The Plant Cell 23, 2196-2208.

Benech-Arnold, R.L. (2004) Inception, maintenance, and termination of dormancy in grain crops: physiology, genetics, and environmental control. pp. 169-198 in Benech-Arnold, R.L.; Sanchez, R.A. (Eds) Handbook of seed physiology. Applications to agriculture. Binghamton, The Haworth Press.

Benech-Arnold, R.L., Giallorenzi, M.C., Frank, J. and Rodríguez, M.V. (1999) Termination of hull-imposed dormancy in developing barley grains is correlated with changes in embryonic ABA levels and sensitivity. Seed Science Research 9, 39-47. 
Benech-Arnold, R.L., Enciso, S., Sánchez, R.A., Carrari, F., Pérez-Flores, L., Iusem, N., Steinbach, H., Lijavetzky, D. and Bottini, R. (2000) Involvement of ABA and GAs in the regulation of dormancy in developing sorghum seeds. pp. 101-111 in Black, M.; Bradford, K.J.; Vázquez Ramos, J. (Eds) Seed biology: Advances and applications. Wallingford, UK, CAB International.

Benech-Arnold, R.L., Enciso, S., Sanchez, R.A. and Rodriguez, M.V. (2003) On the hormonal nature of the stimulatory effect of high incubation temperatures on germination of dormant sorghum (S. bicolor) caryopses. New Phytologist 160, 371-377.

Benech-Arnold, R.L., Gualano, N., Leymarie, J., Côme, D. and Corbineau, F. (2006) Hypoxia interferes with ABA metabolism and increases ABA sensitivity in embryo of dormant barley grains. Journal of Experimental Botany 57, 1423-1430.

Bewley, J.D. (1997) Seed germination and dormancy. The Plant Cell 9, 1055-1066.

Bewley, J.D. and Black, M. (1994) Seeds: Physiology of development and germination. NewYork, Plenum Press.

Biddulph, T.B., Mares, D.J., Plummer, J.A. and Setter, T.L. (2005) Drought and high temperature increases preharvest sprouting tolerance in a genotype without grain dormancy. Euphytica 143, 277-283.

Black, M., Butler, J. and Hughes, M. (1987) Control and development of dormancy in cereals. pp. 379-392 in Mares, D. (Ed.) Proceedings of the 4th Symposium on Pre-harvest Sprouting in Cereals. Boulder, Colorado, USA, Westview Press.

Black, M., Bewley, J.D. and Halmer, P. (2006) The encyclopedia of seeds: Science, technology and uses. Cambridge, USA, CAB International.

Bradford, K.J., Côme, D. and Corbineau, F. (2007) Quantifying the oxygen sensitivity of seed germination using a population-based threshold model. Seed Science Research 17, 33-43.

Bradford, K.J., Benech-Arnold, R., Côme, D. and Corbineau, F. (2008) Quantifying the sensitivity of barley seed germination to oxygen, abscisic acid and gibberellin using a population-based threshold model. Journal of Experimental Botany 59, 335-347.

Cantoro, R., Crocco, C.D., Benech-Arnold, R.L. and Rodríguez, M.V. (2013) In vitro binding of Sorghum bicolor transcription factors ABI4 and ABI5 to a conserved region of a GA 2-OXIDASE promoter: possible role of this interaction in the expression of seed dormancy. Journal of Experimental Botany 64, 5721-5735.

Carrari, F., Perez-Flores, L.J., Lijavetzky, D., Enciso, S., Sánchez, R.A., Benech-Arnold, R.L. and Iusem, N.D. (2001) Cloning and expression of a sorghum gene with homology to maize vp1. Its potential involvement in pre-harvest sprouting resistance. Plant Molecular Biology $45,631-640$.

Chaussat, R. and Zoppolo, J. (1983) Lumière et germination de l'Orge. Bios 14, 30-32.

Chen, C.X., Cai, S.B. and Bai, G.H. (2008) A major QTL controlling seed dormancy and pre-harvest sprouting resitance on chromosome $4 \mathrm{~A}$ in a Chinese wheat land race. Molecular Breeding 21, 351-358.

Chitnis, V.R., Gao, F., Yao, Z., Jordan, M.C., Park, S. and Ayele, B.T. (2014) After-ripening induced transcriptional changes of hormonal genes in wheat seeds: The cases of brassinosteroids, ethylene, cytokinin and salicylic acid.
PLoS ONE 9(1), e87543, doi:10.1371/journal.pone. 0087543.

Chono, M., Matsunaka, H., Seki, M., Fujita, M., KiribuchiOtabe, C., Oda, S., Kojima, H., Kobayashi, D. and Kawakami, N. (2013) Isolation of a wheat (Triticum aestivum L.) mutant in ABA8'-hydroxylase gene: effect of reduced $A B A$ catabolism on germination inhibition under field condition. Breeding Science 63, 104-115.

Clark, L.E., Collier, J.W. and Langston, R. (1967) Dormancy in Sorghum bicolor (L.) Moench. I. Relationship to seed development. Crop Science 7, 497-501.

Cohn, M.A. and Hughes, J. (1981) Seed dormancy in red rice (Oryza sativa). I. Effect of temperature on dry afterripening. Weed Science 29, 402-404.

Collins, F.W. (1986) Oat phenolics: structure, occurrence and function. pp. 227-295 in Webster, F.M. (Ed.) Oats: Chemistry and technology. St Paul, Minnesota, USA, American Association of Cereal Chemists.

Côme, D., Lenoir, C. and Corbineau, F. (1984) La dormance des céréales et son élimination. Seed Science and Technology 12, 629-640.

Côme, D., Corbineau, F. and Lecat, S. (1988) Some aspects of metabolic regulation of cereal seed germination and dormancy. Seed Science and Technology 16, 175-186.

Corbineau, F. and Côme, D. (1980) Quelques caractéristiques de la dormance du caryopse d'Orge (Hordeum vulgare L., variété Sonja). Comptes Rendus de l'Académie des Sciences, Paris, série D 290, 547-550.

Corbineau, F. and Côme, D. (1993) The concept of dormancy in cereal seeds. pp. 581-589 in Côme, D.; Corbineau, F. (Eds) Fourth international workshop on seeds: basic and applied aspects of seed biology. Vol. 2. Paris, ASFIS.

Corbineau, F. and Côme, D. (1996) Barley seed dormancy. Bios Boissons Conditionnement 261, 113-119.

Corbineau, F. and Côme, D. (2000) Dormancy of cereal seeds as related to embryo sensitivity to $\mathrm{ABA}$ and water potential. pp. 183-194 in Viémont, J.-D.; Crabbé, J. (Eds) 2nd International Symposium on Plant Dormancy. Wallingford, UK, CAB International.

Corbineau, F. and Côme, D. (2003) Involvement of energy metabolism and $\mathrm{ABA}$ in primary and secondary dormancies in oat (Avena sativa L.) seeds - a physiological approach. pp. 113-120 in Nicolas, G.; Bradford, K.J.; Côme, D.; Pritchard, H. (Eds) The biology of seeds: Recent research advances. Wallingford, UK, CAB International.

Corbineau, F., Sanchez, A., Côme, D. and Chaussat, R. (1981) La dormance du caryopse de blé (Triticum aestivum L. var. Champlein) en relation avec la température et l'oxygène. Comptes Rendus de l'Académie d'Agriculture de France 9, 826-834.

Corbineau, F., Lecat, S. and Côme, D. (1986) Dormancy of three cultivars of oat seeds (Avena sativa L.). Seed Science and Technology 14, 725-735.

Corbineau, F., Poljakoff-Mayber, A. and Côme, D. (1991) Responsiveness to abscisic acid of embryos of dormant oat (Avena sativa) seeds. Involvement of ABA-inducible proteins. Physiologia Plantarum 83, 1-6.

Corbineau, F., Black, M. and Côme, D. (1993) Induction of thermodormancy in Avena sativa seeds. Seed Science Research 3, 111-117.

Corbineau, F., Benamar, A. and Côme, D. (2000) Changes in sensitivity to ABA of the developing and maturing embryo of two wheat cultivars with different sprouting susceptibility. Israel Journal of Plant Science 48, 189-197. 
Cutler, S.R., Rodriguez, P.L., Finkelstein, R.R. and Abrams, S.R. (2010) Abscisic acid: Emergence of a core signalling network. Annual Review of Plant Biology 61, 651-679.

Davière, J.-M. and Achard, P. (2013) Gibberellin signalling in plants. Development 140, 1147-1151.

Debeaujon, I., Leon-Kloosterziel, K.M. and Koornneef, M. (2000) Influence of the testa on seed dormancy, germination, and longevity in Arabidopsis. Plant Physiology 122, 403-414.

Debeaujon, I., Peeters, A.J., Leon-Kloosterziel, K.M. and Koornneef, M. (2001) The TRANSPARENT TESTA12 gene of Arabidopsis encodes a multidrug secondary transporter-like protein required for flavonoid sequestration in vacuoles of the seed coat endothelium. The Plant Cell 13, 853-871.

Derera, N.F. (1989) The effects of preharvest rain. pp. 1-14 in Derrera, N.F. (Ed.) Preharvest field sprouting in cereals. Boca Raton, Florida, CRC Press.

Edney, M.J., Legge, W.G., Izydorczyk, M.S., Demeke, T. and Rossnagel, B.G. (2013) Identification of barley breeding lines combining preharvest sprouting resistance with 'Canadian-type' malting quality. Crop Science 53, 1447-1454.

Evers, A. and Nesbitt, M. (2006) Cereals. pp. 65-70 in Black, M.; Bewley, J.D.; Halmer, P. (Eds) The encyclopedia of seeds: Science, technology and uses. Wallingford, UK, CAB International.

Fan, J., Niu, X., Wang, Y., Ren, G., Zhuo, T., Yang, Y., Lu, B-R. and Liu, Y. (2007) Short, direct repeats (SDRs)-mediated post-transcriptional processing of a transcription factor gene OsVP1 in rice (Oryza sativa). Journal of Experimental Botany 58, 3811-3817.

Fang, J., Chai, C., Qian, Q., Li, C., Tang, J., Sun, L., Huang, Z., Guo, X., Sun, C., Liu, M., Zhang, Y., Lu, Q., Wang, Y., Lu, C., Han, B., Chen, F., Cheng, Z. and Chu, C. (2008) Mutations of genes in synthesis of the carotenoid precursors of ABA lead to pre-harvest sprouting and photooxidation in rice. Plant Journal 54, 177-189.

Finch-Savage, W.E. and Leubner-Metzger, G. (2006) Seed dormancy and the control of germination. New Phytologist 171, 501-523.

Flintham, J.E. (2000) Different genetic components control coat-imposed and embryo-imposed dormancy in wheat. Seed Science Research 10, 43-50.

Flintham, J.E. and Gale, M.D. (1982) The Tom Thumb dwarfing gene, Rht3 in wheat 1 . Reduced pre-harvest damage to breadmaking quality. Theoretical and Applied Genetics 62, 121-126.

Flintham, J., Adlam, R., Bassoi, M., Holdsworth, M. and Gale, M. (2002) Mapping genes for resistance to sprouting damage in wheat. Euphytica 16, 39-45.

Fofana, B., Humphreys, G., Rasul, G., Cloutier, S., Brule-Babel, A., Woods, S., Lukow, O.M. and Somers, D.J. (2009) Mapping quantitative trait loci controlling pre-harvest sprouting resistance in a red $\times$ white seeded spring wheat cross. Euphytica 165, 509-521.

Gao, F.Y., Ren, G.J., Lu, X.J., Sin, S.X., Li, H.J., Gao, Y.M., Lou, H., Yan, W.E.G. and Zhang, Y.Z. (2008) QTL analysis for resistance to preharvest sprouting in rice (Oryza sativa). Plant Breeding 127, 268-273.

Gendreau, E., Romaniello, S., Barad, S., Leymarie, J., Benech-Arnold, R. and Corbineau, F. (2008) Regulation of cell cycle activity in the embryo of barley seeds during germination as related to grain hydration. Journal of Experimental Botany 59, 203-212.
Gerjets, T., Scholefield, D., Foulkes, M.J., Lenton, J.R. and Holdsworth, M.J. (2010) An analysis of dormancy, ABA responsiveness, after-ripening and pre-harvest sprouting in hexaploid wheat (Triticum aestivum L.) caryopses. Journal of Experimental Botany 61, 597-607.

Gianinetti, A. and Vernieri, P. (2007) On the role of abscisic acid in seed dormancy of red rice. Journal of Experimental Botany 58, 3449-3462.

Gibbs, D.J., Lee, S.C., Isa, N.M., Gramuglia, S., Fukao, T., Bassel, G.W., Correia, C.S., Corbineau, F., Theodoulou, F.L., Bailey-Serres, J. and Holdsworth, M.J. (2011) Homeostatic response to hypoxia is regulated by the $\mathrm{N}$-end rule pathway in plants. Nature 479, 415-418.

Glennie, C.W. (1981) Preharvest changes in polyphenols, peroxidase, and polyphenol oxidase in Sorghum grain. Journal of Agricultural and Food Chemistry 29, 33-36.

Gordon, I.L. (1979) Selection against sprouting damage in wheat. III Dormancy, germinative alpha-amylase, grain redness and flavonols. Australian Journal of Agricultural Research 30, 1-16.

Grahl, A. (1965) Induction of secondary dormancy in wheat by means of high temperature and the effect of the humidity of the seed bed. Proceedings of the International Seed Testing Association 30, 787-801.

Groos, C., Gay, G., Perretant, M.R., Gervais, L., Bernard, M., Dedryver, F. and Charmet, G. (2002) Study of the relationship between preharvest sprouting and grain colour by quantitative trait loci analysis in white $\times$ red grain bread wheat cross. Theoretical Applied Genetics 104, 39-47.

Grotewold, E., Drummond, B.J., Bowen, B. and Peterson, T. (1994) The myb-homologous $P$ gene controls phlobaphene pigmentation in maize floral organs by directly activating a flavonoid biosynthetic gene subset. Cell 76, $543-553$.

Gu, X.Y., Kianian, S.F. and Foley, M.E. (2004) Multiple loci and epistases control genetic variation for seed dormancy in weedy rice (Oryza sativa L.). Genetics 166, 1503-1516.

Gu, X.-Y., Kianian, S.F. and Foley, M.E. (2005) Dormancy imposed by covering tissues interrelated with seed shattering and morphological characteristics in weedy rice (Oryza sativa L.). Crop Science 45, 948-955.

Gu, X.Y., Foley, M.E., Horvath, D.P., Anderson, J.V., Feng, J., Zhang, L., Mowry, C.R., Ye, H., Suttle, J.C., Kadowaki, K. and Chen, Z. (2011) Association between seed dormancy and pericarp color is controlled by a pleiotropic gene that regulates abscisic acid and flavonoid synthesis in weedy red rice. Genetics 189, 1515-1524.

Gualano, N.A. and Benech-Arnold, R.L. (2009a) Predicting pre-harvest sprouting susceptibility in barley: Looking for 'sensitivity windows' to temperature throughout grain filling in various commercial cultivars. Field Crop Research 114, 35-44.

Gualano, N.A. and Benech-Arnold, R.L. (2009b) The effect of water and nitrogen availability during grain filling on the timing of dormancy release in malting barley crops. Euphytica 168, 291-301.

Gualano, N., Carrari, F., Rodríguez, M.V., Pérez-Flores, L., Sánchez, R.A., Iusem, N.D. and Benech-Arnold, R.L. (2007) Reduced embryo sensitivity to ABA in sprouting susceptible sorghum (Sorghum bicolor) variety is associated with an altered ABA signalling. Seed Science Research 17, 81-90. 
Gualano, N.A., Del Fueyo, P.A. and Benech-Arnold, R.L. (2014) Potential longevity (Ki) of malting barley (Hordeum vulgare L.) grain lots relates to their degree of pre-germination assessed through different industrial quality parameters. Journal of Cereal Science 60, 222-228.

Gubler, F., Millar, A.A. and Jacobsen, J.V. (2005) Dormancy release, ABA and pre-harvest sprouting. Current Opinion in Plant Biology 8, 183-187.

Gubler, F., Hughes, T., Waterhouse, P. and Jacobsen, J. (2008) Regulation of dormancy in barley by blue light and after-ripening: effects on abscisic acid and gibberellin metabolism. Plant Physiology 147, 886-896.

Hicky, L.T., Lawson, W., Arief, V.N., Fox, G., Frankowiak, J. and Dieters, M.J. (2012) Grain dormancy QTL identified in a double haploid barley population derived from two non-dormant parents. Euphytica 188, 113-122.

Hilhorst, H.W.M. (2007) Definitions and hypotheses of seed dormancy. pp. 50-71 in Bradford, K.J.; Nonogaki, H. (Eds) Seed development, dormancy, and germination. Oxford, UK, Blackwell Publishing.

Hilhorst, H.W.M., Finch-Savage, W.E., Buitink, J., Bolingue, W. and Leubner-Metzger, G. (2010) Dormancy in plant seeds. pp. 43-67 in Lubzens, E.; Cerdà, J.; Clarck, M. (Eds) Dormancy and resistance in harsh environments. Berlin, Springer-Verlag.

Himi, E. and Noda, K. (2005) Red grain color gene $(R)$ of wheat is a Myb-type transcription factor. Euphytica 143, 239-242.

Himi, E., Mares, D.J., Yanagisawa, A. and Noda, K. (2002) Effect of grain colour gene $(R)$ on grain dormancy and sensitivity of the embryo to abscisic acid (ABA) in wheat. Journal of Experimental Botany 53, 1569-1574.

Himi, E., Nisar, A. and Noda, K. (2005) Colour genes ( $R$ and $R c$ ) for grain and coleoptile upregulate flavonoid biosynthesis genes in wheat. Genome 48, 747-754.

Himi, E., Maekawa, M., Miura, H. and Noda, K. (2011) Development of PCR markers for Tamyb10 related to $R-1$, red grain color in wheat. Theoretical Applied Genetics 122, 1561-1576.

Himi, E., Yamashita, Y., Haruyama, N., Yanagisawa, T., Maekawa, M. and Taketa, S. (2012) Ant28 gene for proanthocyanidin synthesis encoding the R2R3 MYB domain protein (Hvmyb10) highly affects grain dormancy in barley. Euphytica 188, 141-151.

Hoang, H.H., Bailly, C., Corbineau, F. and Leymarie, J. (2013a) Induction of secondary dormancy by hypoxia in barley grains and its hormonal regulation. Journal of Experimental Botany 64, 2017-2025.

Hoang, H.H., Sotta, B., Gendreau, E., Bailly, C., Leymarie, J. and Corbineau, F. (2013b) Water content: a key factor of the induction of secondary dormancy in barley grains as related to ABA metabolism. Physiologia Plantarum 148, 284-296.

Hoang, H.H., Sechet, J., Bailly, C., Leymarie, J. and Corbineau, F. (2014) Inhibition of germination of dormant barley (Hordeum vulgare L.) grains by blue light as related to oxygen and hormonal regulation. The Plant Cell and Environment 37, 1393-1403.

Holman, T.J., Jones, P.D., Russell, L., Medhurst, A., Ubeda Tomás, S., Talloji, P., Marquez, J., Schmuths, H., Tung, S-A., Taylor, I., Footitt, S., Bachmair, A., Theodoulou, F.L. and Holdsworth, M.J. (2009) The N-end rule pathway promotes seed germination and establishment through removal of ABA sensitivity in Arabidopsis. Proceedings of the National Academy of Sciences, USA 106, 4549-4554.
Hori, K., Sugimoto, K., Nonoue, Y., Ono, N., Matsubara, K., Yamanouchi, U., Abe, A., Takeuchi, Y. and Yano, M. (2010) Detection of quantitative trait loci controlling pre-harvest sprouting resistance by using back-crossed populations of japonica rice cultivars. Theoretical Applied Genetics 120, 1547-1557.

Huang, T., Qu, B., Li, H.-P., Zuo, D.-Y., Zhao, Z.-X. and Liao, Y.-C. (2012) A maize viviparous 1 gene increases seed dormancy and preharvest sprouting tolerance in transgenic wheat. Journal of Cereal Science 55, 166-173.

Imtiaz, M., Ogbonnaya, F.C., Oman, J. and Van Ginkel, M. (2008) Characterization of quantitative trait loci controlling genetic variation for pre-harvest sprouting in synthetic backcross-derived wheat lines. Genetics 178, 1725-1736.

Jacobsen, J.V., Pearce, D.W., Poole, A.T., Pharis, R.P. and Mander, L.N. (2002) Abscisic acid, phaseic acid and gibberellin contents associated with dormancy and germination in barley. Physiologia Plantarum 115, 428-441.

Jacobsen, J.V., Barrero, J.M., Hughes, T., Julkowska, M., Taylor, J.M., Xu, Q. and Gubler, F. (2013) Roles for blue light, jasmonate and nitric oxide in the regulation of dormancy and germination in wheat grain (Triticum aestivum L.). Planta 238, 121-138.

Jaiswal, J.V., Mir, R.R., Mohan, A., Balyan, H.S. and Gupta, S.K. (2012) Association mapping for pre-harvest sprouting tolerance in common wheat (Triticum aestivum L.). Euphytica 188, 89-102.

Jayachandran-Nair, K. and Sridhar, R. (1975) Phenolic compounds present in rice husk. Biologia Plantarum 17, 318-319.

Ji, X., Dong, B., Shiran, B., Talbot, M.J., Edlington, J.E., Hughes, T., White, R.G., Gubler, F. and Dolferus, R. (2011) Control of abscisic acid catabolism and abscisic acid homeostasis is important for reproductive stage stress tolerance in cereals. Plant Physiology 156, 647-662.

Juliano, B.O. and Chang, T.-T. (1987) Pre-harvest sprouting in rice. pp. 34-42 in Mares, D.J. (Ed.) Proceedings of the Fourth International Symposium on Pre-Harvest Sprouting in Cereals. Boulder, Colorado, USA, Westview Press.

Karssen, C. and Lacka, E. (1986) A revision of the hormone balance theory of seed dormancy: studies on gibberellin and/or abscisic acid-deficient mutants of Arabidopsis thaliana. pp. 315-323 in Bopp, M. (Ed.) Plant Growth Substances 1985: Proceedings of the 12th International Conference on Plant Growth Substances. Heidelberg, Springer-Verlag.

Kato, K., Nakamura, W., Tabiki, T. and Miura, H. (2001) Detection of loci controlling seed dormancy on group 4 chromosomes of wheat and comparative mapping with rice and barley genomes. Theoretical and Applied Genetics 10, 980-985.

Kawakami, N., Miyake, Y. and Noda, K. (1997) ABA insensitivity and low ABA levels during seed development of non-dormant wheat mutants. Journal of Experimental Botany 48, 1415-1421.

Kent, N.L. and Evers, A.D. (1994) Technology of cereals: An introduction for students of food science and agriculture (4th edition). Oxford, UK, Pergamon Press.

King, R.W. (1983) The physiology of pre-harvest sprouting a review. pp. 11-21 in Kruger, J.E.; Laberge, D.E. (Eds) Proceedings of the Third International Symposium of Pre-harvest Sprouting in Cereals. Boulder, Colorado, USA, Westview Press. 
King, R.W. (1989) Physiology of sprouting resistance. pp. 28-60 in Derrera, N.F. (Ed.) Preharvest field sprouting in cereals. Boca Raton, Florida, CRC Press.

Kobayashi, F., Takumi, S. and Nakamura, C. (2008) Increased freezing tolerance in an ABA-hypersensitive mutant of common wheat. Journal of Plant Science 165, 224-232.

Krogmeier, M.J. and Bremner, J.M. (1989) Effects of phenolic acids on seed germination and seedling growth in soil. Biology and Fertility of Soils 8, 116-122.

Kulwal, P.L., Kumar, N., Gaur, A., Khurana, P., Khurana, J.P., Tyagi, A.K., Balyan, H.S. and Gupta, P.K. (2005) Mapping of a major QTL for pre-harvest sprouting tolerance on chromosome $3 \mathrm{~A}$ in bread wheat. Theoretical and Applied Genetics 11, 1052-1059.

Kulwal, P.L., Mir, R.R., Kumar, S. and Gupta, P.K. (2010) QTL analysis and molecular breeding for seed dormancy and pre-harvest sprouting tolerance in bread wheat. Journal of Plant Biology 37, 59-74.

Kumar, A., Kumar, J., Singh, R., Garg, T., Chuneja, P., Balyan, H.S. and Gupta, P.K. (2009) QTL analysis for grain colour and pre-harvest sprouting in bread wheat. Plant Science 177, 114-122.

Kuwal, P., Ishikawa, G., Benscher, D., Feng, Z., Yu, L.X., Jadhav, A., Mehetre, S. and Sorrells, M.E. (2012) Association mapping for pre-harvest sprouting resistance in white winter wheat. Theoretical and Applied Genetics 125, 793-805.

Lecat, S., Corbineau, F. and Côme, D. (1992) Effects of gibberellic acid on the germination of dormant oat (Avena sativa L.) seeds as related to temperature, oxygen and energy metabolism. Seed Science and Technology 20, 421-433.

Lenoir, C., Corbineau, F. and Côme, D. (1983) Rôle des glumelles dans la dormance des semences d'orge. Physiologie Végétale 21, 633-643.

Lenoir, C., Corbineau, F. and Côme, D. (1986) Barley (Hordeum vulgare) seed dormancy as related to glumellae characteristics. Physiologia Plantarum 68, 301-307.

Lepiniec, L., Debeaujon, I., Routaboul, J.-M., Baudry, A., Pourcel, L., Nesi, N. and Caboche, M. (2006) Genetics and biochemistry of seed flavonoids. Annual Review of Plant Biology 57, 405-430.

Leymarie, J., Robayo-Romero, M.E., Gendreau, E., BenechArnold, R.L. and Corbineau, F. (2008) Involvement of ABA in induction of secondary dormancy in barley (Hordeum vulgare L.) seeds. Plant and Cell Physiology 49, 1830-1838.

Li, C.D., Tarr, A., Lance, R.C., Harasymow, S., Uhlmann, J., Westcot, S., Young, K.J., Grime, C.R., Cakir, M., Broughton, S. and Appels, R. (2003) A major QTL controlling seed dormancy and pre-harvest sprouting/ grain $\alpha$-amylase in two-rowed barley (Hordeum vulgare L.). Australian Journal of Agricultural Research 54, 1303-1313.

Lin, S.Y., Sasaki, T. and Yano, M. (1998) Mapping quantitative trait loci controlling seed dormancy and heading date in rice, Oryza sativa L., using backcross inbred lines. Theoretical and Applied Genetics 96, 997-1003.

Liu, A., Gao, F., Kanno, Y., Jordan, M.C., Kamiya, Y., Seo, L. and Ayele, B. (2013) Regulation of wheat seed dormancy by after-ripening is mediated by specific transcriptional switches that induce changes in seed hormone metabolism and signalling. PLOS ONE 8, e56570, doi:10.1371/ journal.pone.0056570.
Liu, S., Cai, S., Graybosch, R., Chen, C. and Bai, G. (2008) Quantitative trait loci for resistance to pre-harvest sprouting in US hard white winter wheat Rio Blanco. Theoretical and Applied Genetics 117, 691-699.

Liu, S., Sehgal, S.K., Li, J., Lin, M., Trick, H.N., Yu, J., Gill, B.S. and Bai, G. (2013) Cloning and characterization of a critical regulator for preharvest sprouting in wheat. Genetics 195, 263-273.

Lu, B., Xie, K., Yang, C., Wang, S., Liu, X., Zhang, L., Jiang, L. and Wan, J. (2011) Mapping two major effect grain QTL in rice. Molecular Breeding 28, 453-462.

Maiti, R.K., Raju, P.S. and Bidinger, F.R. (1985) Studies on germinability and some aspects of pre-harvest physiology of sorghum grain. Seed Science and Technology 13, $21-35$.

Mares, D.J. (1989) Preharvest sprouting damage and sprouting tolerance: assay methods and instrumentation. pp. 129-170 in Derrera, N.F. (Ed.) Preharvest field sprouting in cereals. Boca Raton, Florida, CRC Press.

Mares, D.J. (1993) Preharvest sprouting in wheat. 1. Influence of cultivar, rainfall and temperature during grain ripening. Australian Journal of Agricultural Research 44, 1259-1272.

Mares, D.J. and Mrva, K. (2001) Mapping quantitative trait loci associated with variation in grain dormancy in Australian wheat. Australian Journal of Agricultural Research 52, 1257-1265.

Mares, D., Mrva, K., Cheong, J., Williams, K., Watson, B., Storlie, E., Sutherland, M. and Zou, Y. (2005) A QTL located on chromosome $4 \mathrm{~A}$ associated with dormancy in white- and red-grained wheats of diverse origin. Theoretical Applied Genetics 111, 1357-1364.

Mares, D., Rathjen, J., Mrva, K. and Cheong, J. (2009) Genetic and environmental control of dormancy in white-grained wheat (Triticum aestivum L.). Euphytica 168, 311-318

Maruyama, K. (1980) Methods of selection against preharvest sprouting of rice during rapid generation advance. Japanese Journal of Breeding 30, 344-350.

McCarty, D.R., Carson, C.B., Stinard, P.S. and Robertson, D.S. (1989) Molecular analysis of Viviparous-1 - an abscisic acid-insensitive mutant of maize. The Plant Cell 1, 523-532.

McKibbin, R.S., Wilkinson, M.D., Bailey, P.C., Flintham, J.E., Andrew, L.M., Lazzeri, P.E., Gale, M.D., Lentone, J.R. and Holdsworth, M.J. (2002) Transcripts of Vp-1 homeologues are misspliced in modern wheat and ancestral species. Proceedings of the National Academy of Sciences, USA 99, 10203-10208.

Meimoun, P., Mordret, E., Langlade, N.B., Balzergue, S., Arribat, C., Bailly, S. and El-Maarouf-Bouteau, H. (2014) Is gene transcription involved in seed dry after-ripening? PLOS ONE 9, e86442, doi:10.1371/journal.pone.0086442.

Mendiondo, G.M., Leymarie, J., Farrant, J.M., Corbineau, F. and Benech-Arnold, R.L. (2010) Differential expression of abscisic acid metabolism and signalling genes induced by seed covering structures or hypoxia in barley (Hordeum vulgare L.) grains. Seed Science Research 20, 69-77.

Meredith, P. and Pomeranz, Y. (1985) Sprouted grain. pp. 239-320 in Pomeranz, Y. (Ed.) Advances in cereal science and technology. St Paul, Minnesota, US Department of Agriculture.

Millar, A.A., Jacobsen, J.V., Ross, J.J., Helliwell, C.A., Poole, A.T., Scofield, G., Reid, J.B. and Gubler, F. (2006) 
Seed dormancy and ABA metabolism in Arabidopsis and barley: the role of ABA8'-hydroxylase. The Plant Journal 45, 942-954.

Mori, M., Uchino, N., Chono, M., Kato, K. and Miura, H. (2005) Mapping QTLs for grain dormancy on wheat chromosome $3 \mathrm{~A}$ and the group 4 chromosomes, and their combined effect. Theoretical Applied Genetics 100, 1257-1266.

Morris, F., Moffatt, J.M., Sears, R.G. and Paulsen, G.M. (1989) Seed dormancy and responses of caryopses, embryos and calli to abscisic acid. Plant Physiology 90, 643-647.

Nakamura, S., Abe, F., Kawahigashi, H., Nakazono, K., Tagiri, A., Matsumoto, T., Utsugi, S., Ogawa, T., Handa, H., Ishida, H., Mori, M., Kawaura, K., Ogihara, Y. and Miura, H. (2011) A wheat homolog of MOTHER OF FT AND TFL1 acts in the regulation of germination. The Plant Cell 23, 3215-3229.

Nambara, E. and Marion-Poll, A. (2003) ABA action and interaction in seeds. Trends in Plant Science 8, 213-217.

Nambara, E., Okamoto, M., Tatematsu, K., Yano, R., Seo, M. and Kamiya, Y. (2010) Abscisic acid and the control of seed dormancy and germination. Seed Science Research 20, 55-67.

Neill, S., Horgan, R. and Rees, A.F. (1987) Seed development and vivipary in Zea mays L. Planta 171, 358-364.

Nonogaki, M., Sali, K., Nambara, E. and Nonogaki, H. (2014) Amplification of ABA biosynthesis and signalling through a positive feedback mechanism in seeds. Plant Journal 78, 527-539.

Ogbonnaya, F.C., Imtiaz, M., Ye, G., Hearnden, P.R., Hernandez, E., Eastwood, R.F., van Ginkel, M., Shorter, S.C. and Winchester, J.M. (2008) Genetic and QTL analyses of seed dormancy and preharvest sprouting resistance in the wheat germplasm CN10955. Theoretical and Applied Genetics 116, 891-902.

Oki, T., Masuda, M., Kobayashi, M., Nishiba, Y., Furuta, S., Suda, I. and Sato, T. (2002) Polymeric procyanidins as radical-scavenging components in red-hulled rice. Journal of Agricultural and Food Chemistry 50, 7524-7529.

Oracz, K., Bouteau, H.E.-M., Farrant, J.M., Cooper, K., Belghazi, M., Job, C., Job, D., Corbineau, F. and Bailly, C. (2007) ROS production and protein oxidation as a novel mechanism for seed dormancy alleviation. Plant Journal 50, 452-465.

Osa, M., Kato, K., Mori, M., Shindo, C., Torada, A. and Miura, H. (2003) Mapping QTLs for seed dormancy and the VP1 homologue on Chromosome 3A in wheat. Theoretical and Applied Genetics 106, 1491-1496.

Rathi, S., Pathak, K., Yadav, R.N.S., Kumar, B. and Sama, R.N. (2014) Association studies of dormancy and cooking quality traits in direct-seeded indica rice. Journal of Genetics 93, 3-12.

Rathjen, J.R., Strounina, E.V. and Mares, D.J. (2009) Water movement into dormant and non-dormant wheat (Triticum aestioum L.) grains. Journal of Experimental Botany 60, 1619-1631.

Reddy, V.S., Dash, S. and Reddy, A.R. (1995) Anthocyanin pathway in rice (Oryza sativa L.): identification of a mutant showing dominant inhibition of anthocyanins in leaf and accumulation of proanthocyanidins in pericarp. Theoretical and Applied Genetics 91, 301-312.

Rehman Arif, M.A., Neumann, K., Nagel, M., Kobiljski, B., Lohwasser, U. and Borner, A. (2012) An association mapping analysis of dormancy and pre-harvest sprouting in wheat. Euphytica 188, 409-417.

Ried, J.L. and Walker-Simmons, M.K. (1990) Synthesis of abscisic acid-responsive, heat-stable proteins in embryonic axes of dormant wheat grain. Plant Physiology 93, 662-667.

Rikiishi, K. and Maekawa, M. (2010) Characterization of a novel wheat (Triticum aestivum L.) mutant with reduced seed dormancy. Journal of Cereal Science 51, 292-298.

Robichaud, C.S. and Sussex, I.M. (1986) The response of viviparous1 and wild-type embryos of Zea mays to culture in the presence of abscisic acid. Journal of Plant Physiology 126, 235-242.

Rodriguez, M.V., González Martín, J., Insausti, P., Margineda, J.M. and Benech-Arnold, R.L. (2001) Predicting preharvest sprouting susceptibility in barley: a model based on temperature during grain filling. Agronomy Journal 93, 1071-1079.

Rodríguez, M.V., Mendiondo, G.M., Maskin, L., Gudesblat, G.E, Iusem, N.D. and Benech-Arnold, R.L. (2009) Expression of ABA signalling genes and ABI5 protein levels in imbibed Sorghum bicolor caryopses with contrasting dormancy and at different developmental stages. Annals of Botany 104, 975-985.

Rodríguez, M.V., Mendiondo, G.M., Cantoro, R., Auge, G.A., Luna, V., Masciarelli, O. and Benech-Arnold, R.L. (2012) Expression of seed dormancy in grain sorghum lines with contrasting pre-harvest sprouting behavior involves differential regulation of gibberellin metabolism genes. Plant and Cell Physiology 53, 64-80.

Schramm, E.C., Abellara, J.C., Strader, L.C., Campbell, K.G. and Steber, C.M. (2010) Isolation of ABA-responsive mutants in allohexaploid bread wheat (Triticum aestioum L.): drawing connections to grains dormancy, preharvest sprouting, and drought tolerance. Plant Science 179, 620-629.

Schramm, E.C., Nelson, S.K. and Steber, C.M. (2012) Wheat ABA-insensitive mutants result in reduced grain dormancy. Euphytica 188, 35-49.

Schramm, E.C., Nelson, S.K., Kidwell, K.K. and Steber, C.M. (2013) Increased ABA sensitivity results in higher seed dormancy in soft white spring wheat cultivar 'Zak'. Theoretical and Applied Genetics 126, 791-803.

Seo, M., Hanada, A., Kuwahara, A., Endo, A., Okamoto, M., Yamauchi, Y., North, H., Marion-Poll, A., Sun, T.P., Koshiba, T., Kamiya, Y., Yamaguchi, S. and Nambara, E. (2006) Regulation of hormone metabolism in Arabidopsis seeds: phytochrome regulation of abscisic acid metabolism and abscisic acid regulation of gibberellin metabolism. The Plant Journal 48, 354-366.

Simpson, G.M. (1990) Seed dormancy in grasses. Cambridge, Cambridge University Press.

Singh, R., Matus-Cadiz, M., Baga, M., Hucl, P. and Chibbar, R.N. (2010) Indentification of genomic regions associated with seed dormancy in white-grained wheat. Euphytica 174, 391-408.

Slominski, B.A. (1980) Phenolic acids in the meal of developing and stored barley grains. Journal of the Science of Food and Agriculture 31, 1007-1010.

Small, J.G.C., Spruit, C.J.P., Blaauw-Jansen, G. and Blaauw, O.H. (1979) Action spectra for light-induced germination in dormant lettuce seeds. Planta 144, 133-136.

Steinbach, H.S., Benech-Arnold, R.L., Kristof, G., Sanchez, R.A. and Marcucci-Poltri, S. (1995) Physiological basis of pre-harvest sprouting resistance in Sorghum bicolor (L.) Moench. ABA levels and sensitivity in developing 
embryos of sprouting resistant and susceptible varieties. Journal of Experimental Botany 45, 701-709.

Steinbach, H.S., Benech-Arnold, R.L. and Sánchez, R.A. (1997) Hormonal regulation of dormancy in developing sorghum seeds. Plant Physiology 113, 149-154.

Sugimoto, K., Takeuchi, Y., Ebana, K., Miyao, A., Hirochika, H., Hara, N., Ishiyama, K., Kobayashi, M., Ban, Y., Hattori, T. and Yano, M. (2010) Molecular cloning of $S d r 4$, a regulator involved in seed dormancy and domestication of rice. Proceedings of the National Academy of Sciences, USA 107, 5792-5797.

Sweeney, M.T., Thomson, M.J., Pfeil, B.E. and McCouch, S.R. (2006) Caught red-handed: Rc encodes a basic helixloop-helix protein conditioning red pericarp in rice. The Plant Cell 18, 283-294.

Sweeney, M.T., Thompson, M.J., Cho, Y.G., Park, Y.J., Williamson, S.H., Bustmante, S.D. and McCouch, S.R. (2007) Global dissemination of a single mutation conferring white pericarp in rice. PLoS Genetics 3, e133, doi10.1371/journalpgen.0030133.

Takeuchi, Y., Lin, S.Y., Sasaki, T. and Yano, M. (2003) Fine linkage mapping enables dissection of closely linked quantitative trait loci for seed dormancy and heading in rice. Theoretical Applied Genetics 101, 1174-1180.

Tan, B.C., Schwartz, S., Zeevaart, J.A. and McCarty, D.R. (1997) Genetic control of abscisic acid synthesis in maize. Proceedings of the National Academy of Sciences, USA 94, 12235-12240.

Tian, S., Nakamura, K. and Kayara, H. (2004) Analysis of phenolic compouds in white rice, brown rice and germinated brown rice. Journal of Agricultural and Food Chemistry 52, 4808-4813.

Torada, A., Koike, M., Ikeguchi, S. and Tsutsui, I. (2008) Mapping of a major locus controlling seed dormancy using backcrossed progenies in wheat (Triticum aestivum L.). Genome 51, 426-432.

Walker-Simmons, M. (1987) ABA levels and sensitivity in developing wheat embryos of sprouting resistant and susceptible cultivars. Plant Physiology 84, 61-66.

Walker-Simmons, M. (1988) Enhancement of ABA responsiveness in wheat embryos by high temperature. Plant, Cell and Environment 11, 769-775.

Wang, L., Cheng, J., Lai, Y., Du, W., Huang, X., Wang, Z. and Zhang, H. (2014) Identification of QTLs with additive, epistatic and QTL $\times$ development interaction effects for seed dormancy in rice. Planta 239, 411-420.

Wang, M., Heimovaara-Dijkstra, S. and Van Duijn, B. (1995) Modulation of germination of embryos isolated from dormant and non-dormant barley grains by manipulation of endogenous abscisic acid. Planta 195, 586-592.

Wang, M., van der Meulen, R.M., Visser, K., Van Schaik, H.-P., Van Duijn, B. and de Boer, A.H. (1998) Effects of dormancy-breaking chemicals on ABA levels in barley grain embryos. Seed Science Research 8, 129-137.

Warner, R.L., Kudrna, D.A., Spaeth, S.C. and Jones, S.S. (2000) Dormancy in white-grained mutants of Chinese Spring wheat (Triticum aestivum L.). Seed Science Research 10, 51-60.
Weidner, S., Paprocka, J., Kamieniecki, B. and Zadernowski, R. (1993) The role of phenolic acids in dormancy of barley caryopses. pp. 200-211 in Walker-Simmons, W.K.; Ried, J.L. (Eds) Preharvest Sprouting in Cereals 1992. St Paul, Minnesota, USA, American Association of Cereal Chemists.

Weidner, S., Amarowicz, R., Karamac, M. and Dabrowski, G. (1999) Phenolic acids in caryopses of two cultivars of wheat, rye and triticale that display different resistance to preharvest sprouting. European Food Research Technology 210, 109-113.

Weidner, S., Amarowicz, R., Karamac, M. and Fraczek, E. (2000) Changes in endogenous phenolic acids during development of Secale cereal caryopses and after dehydration treatment of unripe rye grains. Plant Physiology and Biochemistry 38, 595-602.

Weidner, S., Krupa, U., Amarowicz, R., Karamac, M. and Abe, S. (2002) Phenolic compounds in embryos of triticale caryopses at different stages of development and maturation in normal environment and after dehydration treatment. Euphytica 126, 115-122.

White, C.N. and Rivin, C.J. (2000) Gibberellins and seed development in maize. II. Gibberellin synthesis inhibition enhances abscisic acid signalling in cultured embryos. Plant Physiology 122, 1089-1097.

White, C.N., Proebsting, W.M., Hedden, P. and Rivin, C.J. (2000) Gibberellins and seed development in maize. I. Evidence that gibberellin/abscisic acid balance governs germination versus maturation pathways. Plant Physiology 122, 1081-1088.

Wilkinson, M., Lenton, J. and Holdsworth, M. (2005) Transcripts of $V p-1$ homeologues are alternatively spliced within the Triticeae tribe. Euphytica 143, 243-246.

Winkel-Shirley, B. (1998) Flavonoids in seeds and grains: physiological function, agronomic importance and the genetics of biosynthesis. Seed Science Research 8, 415-422.

Winkel-Shirley, B. (2001) Flavonoid biosynthesis. A colorful model for genetics, biochemistry, cell biology, and biotechnology. Plant Physiology 126, 485-493.

Xi, W., Liu, C., Hou, X. and Yu, H. (2010) MOTHER OF FT AND TFL1 regulates seed germination through a negative feedback loop modulating ABA signalling in Arabidopsis. The Plant Cell 22, 1733-1748.

Zeevaart, J.A.D. and Creelman, R.A. (1988) Metabolism and physiology of abscisic acid. Annual Review of Plant Physiology 39, 439-473.

Zhang, X.Q., Li, C.D., Tay, A., Lance, R., Mares, D., Cheong, J., Cakir, M., Ma, J.H. and Appels, R. (2008) A new PCR-based marker on chromosome 4AL for resistance to pre-harvest sprouting in wheat (Triticum aestivum L.). Molecular Breeding 22, 227-236.

Zhang, X.R., Garreton, V. and Chua, N.H. (2005) The AIP2 E3 ligase acts as a novel negative regulator of ABA signalling by promoting $\mathrm{ABI} 3$ degradation. Genes $\mathcal{E}$ Development 19, 1532-1543.

Zhang, Y., Miao, X., Xia, X. and He, Z. (2014) Cloning of seed dormancy genes (TaSdr) associated with tolerance to preharvest sprouting in common wheat and development of a functional marker. Theoretical and Applied Genetics $127,855-866$. 